\title{
El debate político y la guerra civil en el Estado de Bolívar y la Confederación Granadina (1859-1862)
}

\section{Luis Miguel Pardo Bueno* luismiguel825@ hotmail.com}

Recibido: mayo de 2015

Aprobado: noviembre de 2015

Resumen: El presente escrito estudia los antecedentes políticos de la guerra civil de 1859- 1862 en el Estado de Bolívar y en la Confederación Granadina. Por una parte, centra su atención en el enfrentamiento político partidista por determinar el alcance de la legislación nacional de 1859 en los Estados de la Confederación; por otra parte, explora las consecuencias de la promulgación de las leyes nacionales de 1859 como los motivos, a nivel local y regional, de la participación del Estado de Bolívar en la guerra civil. Para lograr nuestro propósito, nos enfocamos en las disputas entre el poder central y los poderes provinciales por determinar la legislación que mejor respondiera a los intereses de las élites en el poder regional; de manera que el estudio del debate jurídico entre los partidos liberal y conservador por monopolizar y controlar las elecciones, los cargos públicos, las rentas, la justicia y las armas, fueron temas determinantes en la articulación de las facciones partidistas con distintos grupos socioeconómicos de poder provincial, que se enfrentaron desde las localidades por establecer un nuevo orden constitucional.

Palabras clave: Confederación Granadina, Estado de Bolívar, guerra civil, federalismo, partidos políticos, ejércitos federales.

\footnotetext{
* Maestría en Historia por la Universidad Nacional de Colombia (sede Bogotá). Estudiante del doctorado en Historia por la Universidad Nacional de Colombia (sede Medellín). Agosto de 2014.
}

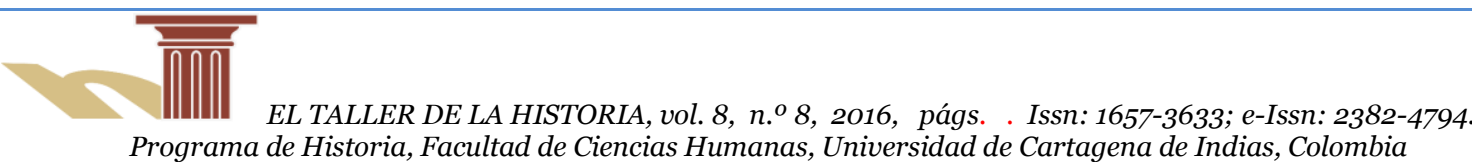




\begin{abstract}
The present article studies the causes of the Civil War 1859 - 1862 in the state of Bolívar and the Grenadine Confederation. On the one hand, focuses on the partisan political showdown to determine the scope of the national legislation of 1859 in the States of the Confederacy; on the other hand, explores the consequences of the enactment of national laws and the reasons 1859, at local and regional level, the participation of the State of Bolivar in the civil war. To achieve our purpose, we focus on disputes between the central government and provincial authorities to determine the law that best respond to the interests of regional elites in power; so that the study of the legal debate between liberal and conservative parties to monopolize and control the elections, public charges, rents, justice and weapons were critical issues in the articulation of partisan factions with different socio-economic groups to provincial, who fought from the localities to establish a new constitutional order.
\end{abstract}

Keywords: Grenadine Confederation, State of Bolivar, civil war, federalism, political parties, federal armies.

\title{
Introducción
}

El presente artículo pretende establecer las motivaciones políticas, económicas y sociales que desataron el conflicto armado de 1859 en el Estado de Bolívar y en la Confederación Granadina. Primero, describimos el enfrentamiento político provincial y nacional, como determinante en las relaciones de poder entre los grupos de notables locales, que buscaron a través de acciones legales establecer un orden político y económico, según sus ideales de organización del Estado para llevar sus demandas e intereses a nivel nacional. Segundo, estudiamos la articulación partidista de las élites provinciales por el monopolio y control de los cargos públicos, las elecciones, la milicia, la justicia y las rentas en el Estado de Bolívar.

Para lograr los objetivos propuestos tomamos elementos del modelo explicativo belicista de Charles Tilly, el cual concibe al Estado como una organización con poder coercitivo que surge de la competencia de grupos sociales por el control de territorios y poblaciones en un proceso por concentrar y acumular los recursos fiscales y coercitivos a través de la lucha armada ${ }^{1}$. La guerra, según Tilly, actúa concentrando atributos y facultades en determinados grupos sociales, los cuales centralizan el poder político, económico y militar permitiéndoles administrar justicia,

${ }^{1}$ Tilly, Charles, “Cambio social y revolución en Europa, 1492-1992”, Historia social, 15, España, Fundación Instituto de Historia Social, 1993, p. 77. 
establecer leyes y fijar impuestos. De manera que el proceso de organizar y poner a funcionar un aparato militar legítimo estatal creó la estructura e instituciones del Estado, instauró la soberanía de un grupo social específico que administra la violencia y extrae los recursos necesarios para ejercerla a través de la guerra, e impone una forma de dominación para el sostenimiento del poder².

El proceso de centralizar y monopolizar el poder político, económico y militar, debió enfrentar la resistencia de los distintos grupos provinciales contra la penetración de instituciones y funcionarios públicos foráneos ${ }^{3}$. Las alianzas y conflictos entre los notables provinciales, generaron identidades colectivas materializadas en vínculos familiares, partidistas y de compadrazgo, por la defensa de sus intereses económicos y políticos en la región. Así, la identidad colectiva estuvo relacionada con la creación discursiva de la Nación, parte esencial en la construcción del Estado y el reconocimiento del grupo humano como comunidad política en un territorio4.

Para el caso colombiano, la independencia de la corona española planteó a los nacientes partidos políticos la necesidad de reformar las instituciones estatales y las relaciones de poder entre el centro político y las provincias. Los partidos proyectaron una serie de cambios al ordenamiento político, económico y social en la Nueva Granada que generaron diferentes conflictos militares en la construcción del Estado en la segunda mitad del siglo XIX. Alrededor de las luchas armadas se configuraron discursos partidistas que definieron la Nación, concibieron la estructura del Estado y sus instituciones, y articularon a las élites nacionales y provinciales entorno a los partidos políticos y sus agendas legislativas5.

2 Tilly, Charles, Coerción, capital y los estados europeos 990-199o, Madrid, Alianza Editorial, 1992, p. 152.

3 El enfrentamiento político y militar por centralizar el poder genera un tipo de dominación (indirecta) que caracteriza a un Estado en ejercicio de sus funciones negociando con los poderes provinciales para ajustar su normatividad y administración pública a situaciones particulares, y que comparte el monopolio de la fuerza y la justicia con los poderes locales. Ver: Elías, Norbert, El proceso de la civilización. Investigaciones socio-genéticas y psicogenéticas, México, Fondo de Cultura Económica, 1987, p. 333.

4 Benedict, Anderson, Comunidades imaginadas. Reflexiones sobre el origen y la difusión del nacionalismo, México, Fondo de Cultura Económica, 1983, p. 23.

5 Koning, Hans Joachim, En el camino hacia la nación: nacionalismo en el proceso de formación del estado y la nación de la Nueva Granada, 1750-1856, Bogotá, Banco de la república, 1994, pp. 28-29; Samper, José María, Los partidos políticos en Colombia, Bogotá, Incunables, 1984, pp. 7-8. 
Nuestro interés se centra en la disputa política que desató la promulgación de la legislación conservadora de 1859 y que motivó el inicio de la guerra civil local en el Estado de Bolívar y su participación en la guerra nacional de 1860- 1862. A continuación exploramos, por una parte, la lucha partidista entre el poder central que se pretendía establecer en Bogotá y las estrategias legales conservadoras para dominar el territorio nacional; y por otra parte, la resistencia de los intermediarios políticos del Estado de Bolívar por mantener el control y el monopolio partidista de las instituciones centrales del Estado en la región, y de esta forma, negociar sus competencias y autonomía con el poder central.

Con el presente estudio abordamos la disputa política como una forma de ma de lucha por establecer un tipo de dominación diferente en la sociedad y para para cambiar las relaciones de poder entre sus miembros. De manera que el derecho sirve como estrategia para desarrollar y mantener normas y políticas imcas impositivas dentro de un orden de legitimidad. Una vez agotados los recursos cursos políticos, la guerra civil se desató para fijar una relación de fuerza y sostener sostener una forma de dominación, así, la política y la guerra actúan como medios medios que dinamizan las sociedades y producen sus cambios ${ }^{6}$.

La importancia del estudio del conflicto político de 1859 radica en la redefinición de la soberanía del Estado, el fortalecimiento de los poderes provinciales y la formación de burocracias armadas partidistas en constante disputa por el poder. Asimismo, el conflicto actúo como constructor del Estado nacional y definió su estructura institucional, fijó una serie de derechos civiles y ciudadanos, instauró una relación entre el dominio nacional y la autonomía provincial, es decir, fue un conflicto por determinar el orden político, librado a través de la opinión pública, las leyes, los decretos, las constituciones y los discursos partidistas. En definitiva, una lucha por el control y dominio de territorios y poblaciones que se desarrolló a partir de lealtades políticas de grupos de ciudadanos ligados a intereses provinciales y locales por el acceso al poder7.

\footnotetext{
${ }^{6}$ Foucault, Michel, Genealogía del racismo, Madrid, Ediciones de la Piqueta, 1992, pp. 49- 74; Abello, Ignacio, "El concepto de la guerra en Foucault", Revista de Estudios sociales, 14, Bogotá, Universidad de los Andes, Febrero de 2003, pp. 71-72-73.

7 Uribe, María Teresa y López Lopera, Liliana María, Las palabras de la guerra. Un estudio sobre las memorias de las guerras civiles en Colombia, Medellín, La Carreta editores, 2006, pp. 36-39; Muñoz Tejada, Julián Andrés, "La guerra civil de 1859: discursos sobre la construcción de un orden”, Revista diálogos de derecho y política, 4, Medellín, Universidad de Antioquia, Mayo- agosto
} 


\section{1.- El contexto político nacional}

La victoria militar del partido conservador en la guerra civil de 1854 y la división liberal entre gólgotas y draconianos, marcó el inicio del relevo burocrático partidista en las provincias 8 de la costa caribe. Un claro ejemplo fue la destitución en 1855 del gobernador liberal de Cartagena Juan José Nieto, acusado por el procurador Lino de Pombo de prevaricato por su apoyo al golpe de Melo y por anteponer su autoridad provincial a la nacional9. En reemplazo de Nieto se nombró a Juan Antonio Calvo, miembro de una tradicional familia conservadora aliada a Mariano Ospina Rodríguez. La destitución de Nieto originó una serie de luchas partidistas por el monopolio de los cargos públicos en las localidades del Estado de Bolívar, la prensa regional y nacional registró los ataques armados, saqueos, persecuciones, encarcelamientos y expropiaciones entre los miembros de los partidos de la siguiente manera: "...los del "barrio de arriba" (liberales) son atacados constantemente por los del "barrio de abajo" (conservadores), siendo víctimas de expropiaciones y asesinatos. Con el nombramiento de José María Gutiérrez de Piñerez prefecto de Mompós, muchas personas han salido de la ciudad para evitar crímenes en su persona y propiedades por parte de los conservadores comandados por Piñerez"10.

de 2010, pp. 4-5; Cardona Tobón, Alfredo, Los caudillos del desastre. Guerras civiles en el siglo $X I X$, Manizales, Hoyos Editores, 2006, p.103.

${ }^{8}$ La provincia designa un territorio sometido militarmente y administrado por un enviado del centro político. Este concepto proviene de la experiencia político-militar medieval europea heredada de la tradición imperial romana y usada por los españoles en la conquista de América. Las provincias neogranadinas configuraron poderes locales débilmente articulados al poder central en Bogotá. El proceso independentista del actual territorio colombiano articuló a las familias de élites provinciales en torno a los nacientes partidos (liberal- conservador). Los reclamos de autonomía política y económica provincial desembocaron en la instauración de una forma de gobierno federal. Los Estados federales creados en 1857 representaron el poder local de las suprimidas provincias de las cuales surgen las jurisdicciones políticas y administrativas del territorio conocido como Estado de Bolívar, compuesto por las antiguas provincias de Cartagena, Sabanilla y parte de la de Mompós.

9 Nieto, Juan José, El ciudadano Juan José Nieto, gobernador suspendido de la provincia de Cartagena, ante los hombres honrados e imparciales de todos los partidos, Bogotá, Imprenta del neogranadino, 1855 , pp. 7-8.

${ }_{10}$ Toda la prensa citada en este artículo se encuentra en la Biblioteca Nacional de Colombia (BNC), El progreso, periódico político de comercio y literatura, No 1, Barranquilla, 1 de octubre de 1857, p. 2; ver también: La Patria, No 50, Bogotá, 19 de junio de 1858, p. 95; El Porvenir, No 299, Bogotá, 17 
En 1856 el procurador general Florentino González advirtió al presidente Manuel Mallarino sobre las múltiples intervenciones de políticos provinciales con fraudes eleccionarios y el uso de la fuerza pública local para sostenerse en el poder. González informó: "las divisiones internas en las administraciones locales se dan por las pretensiones de los partidos las cuales llegan a producir una extensa perturbación del orden, el cual es dejado en manos de la autoridad municipal para ser restablecido. Al tiempo que el gobierno nacional se mezcla en las disputas partidistas locales dando apoyo a uno u otro partido con la fuerza pública"11.

De esta manera, el fraude eleccionario y el uso de la fuerza pública al mando de gobernadores y alcaldes afiliados a un partido político, fueron las principales formas de sostenerse en el poder local ${ }^{12}$. Las familias notables en las localidades del Estado de Bolívar formaron sus propios cuerpos armados y clientelas políticas, se articularon a través de lazos de amistad y compadrazgo, y se vincularon a un partido político identificándose con determinados intereses socioeconómicos. En las localidades los partidos estaban representados por gamonales y caciques que se articulaban a nivel provincial con caudillos encargados de llevar sus demandas a nivel nacional ${ }^{13}$.

En 1857 la elección de Mariano Ospina Rodríguez para el ejecutivo nacional y la instalación del congreso de mayoría conservadora en 1858, llevó a la marginación liberal de los cargos públicos. Los reclamos del liberalismo se centraron en los siguientes temas: el fraude electoral conservador, el monopolio nacional y provincial de los cargos públicos por los conservadores, el uso partidista de la fuerza pública, la pretensión del gobierno de Ospina de monopolizar las rentas de los Esta-

de enero de 1860, p. 788; El Tribuno, No 12, Cartagena, 16 de octubre de 1855, pp. 1-2-3; El Registro Oficial, No 1, Cartagena, 21 de abril de 1858, pp. 1-2-3.

${ }_{11}^{11}$ Informe del procurador general de la nación al secretario de gobierno sobre el estado de la justicia en la Nación, Gaceta Oficial, No 1888, Bogotá, 1856, p. 6.

12 Un juicio imparcial. Unos imparciales, Hoja Suelta, Riohacha, 7 de septiembre de 1855; Exposición del secretario de gobierno al congreso de 1856, Gaceta Oficial, No 1902, Bogotá, 1856, p. 71; Pinzón Lewin, Patricia, El ejército y las elecciones, Bogotá, CEREC, 1994, pp. 29-30-31.

13 Pardo, Luis Miguel, "Gobierno político y militar en el Estado soberano de Bolívar 1857- 1886", Anuario de Historia Regional y de las fronteras, 17 (2), Bucaramanga, Universidad Industrial de Santander, 2013, pp. 215-216; Pardo, Luis Miguel, "Las milicias del Estado Soberano de Bolívar, 1857- 1885", Rueda Cardozo, Juan Alberto (ed.), Los ejércitos federales de Colombia, 1855-1886, Bucaramanga, Universidad Industrial de Santander, COLCIENCIAS, 2013, pp. 92-93. 
dos, la persecución contra los líderes liberales, el apoyo del gobierno nacional a los levantamientos armados conservadores contra los gobiernos seccionales liberales en los Estados de Magdalena y Santander, la creación de Estados federales sin constitución ni leyes que los relacionen y el anuncio de una asamblea nacional constituyente sin la participación de los líderes liberales. Estos aspectos articularon a la facción gólgota y draconiana para calificar al gobierno de Ospina como: “...intruso, ilegal y conspirador, enemigo de la federación con la intensión de centralizar el poder bajo el nombre de la Confederación Granadina para gobernar con y para su partido" 14.

Por su parte, el partido conservador rechazó las acusaciones liberales y señaló a los gólgotas como los causantes de las revueltas armadas en Santander y Magdalena para propiciar ofensas contra la figura del presidente. Los conservadores instalados en el poder nacional y con el dominio en los Estados de Antioquia, Cundinamarca, Boyacá y Bolívar, enfrentaban a sus últimos opositores radicales en los Estados de Santander y Magdalena, mientras el Estado del Cauca estaba bajo la influencia del general Mosquera. Por consiguiente, el partido conservador estableció la constitución de 1858 que materializaba, sobre el papel, las pretensiones de autonomía provincial y descentralización económica, política y militar planteada desde 1835 por Juan José Nieto para las provincias de la costa caribe. Sin embargo, para la prensa liberal, la constitución fue, al mismo tiempo, un ataque a los intermediarios provinciales que no pertenecieran a los círculos políticos, económicos, familiares y militares del partido conservador, ya que les negaba el acceso a los cargos públicos locales ${ }^{15}$.

\footnotetext{
14 La Causa del pueblo, No 2, Bogotá, 17 de mayo de 1859, p. 1; ver también: La Patria, No 32, Bogotá, 6 de febrero de 1858, p. 21; La Patria, No 18, Bogotá, 15 de octubre de 1857, p. 70; El Núcleo, No 1, Bogotá, 26 de enero de 1858, p. 4; Restrepo, José Manuel, Diario político y militar, memorias sobre los sucesos importantes de la época para servir a la historia de la revolución de Colombia y de la Nueva Granada, desde 1849 para adelante, Bogotá, Imprenta nacional, 1954, tomo IV, p. 693; Guerra, José Joaquín, Estudios históricos, Bogotá, Biblioteca Popular de cultura colombiana, 1952, tomo I, pp. 207-208-236-237-239; Núñez, Rafael, "La paz científica”, Múnera, Alfonso (Comp.), Ensayos costeños. De la colonia a la república: 1770-1890, Bogotá, Colcultura, 1994, p. 446.

15 Nieto, Juan José, "Correspondencia dirigida al general Francisco de Paula Santander, 7 de agosto de 1835”, Bell Lemus, Gustavo (Comp.), Nieto Juan José, selección de textos políticos-geográficos e históricos, Bogotá, Ediciones gobernación del Atlántico, 1993, pp. 20-23; Restrepo Piedrahita, Carlos, Constituciones políticas nacionales de Colombia, Bogotá, Universidad Externado de Colombia, 1995, pp. 995- 1002; La Patria, No 56, Bogotá, 13 de marzo de 1858, p. 38.
} 
Consecuentemente, la interpretación de la constitución de 1858 se dividió entre dos puntos de vista: el primero (conservador), concebía a los Estados como subordinados al gobierno general y planteó la reforma a la legislación sobre elecciones, justicia, hacienda y fuerza pública nacional, la cual debía ser determinada por los altos poderes nacionales para extraerla de la influencia y de las "manos caprichosas y arbitrarias de las cámaras de provincia”. La segunda interpretación (liberal), asumía que los Estados tenían libertad legal y constitucional de imponer su legislación fiscal y militar, y denunciaba las pretensiones conservadoras de centralizar el poder político y recortar la soberanía y las libertades de los Estados ${ }^{16}$.

En general, la constitución de 1858 determinó que las autoridades de los Estados debían cumplir y ejecutar la constitución, leyes, decretos y órdenes del presidente (capítulo 2, artículo 10). Asimismo, al gobierno general le correspondía la organización y reforma del gobierno de la Confederación, mantener el orden y tranquilidad disponiendo de la fuerza pública y vigilar el cumplimiento de las leyes nacionales a través de agentes del gobierno central enviados a los Estados (sección $5^{\mathrm{a}}$, artículo 13-45). Estas disposiciones fueron vistas por el liberalismo radical como una violación a la autonomía provincial y la usurpación de los derechos ciudadanos. Igualmente, el discurso liberal de la traición conservadora al pacto federal y la tiranía de Ospina, configuró la justificación del derecho para apelar a las armas y autoproclamarse "salvadores de la república federal", así el liberalismo radical estableció una conexión con la guerra como medio para reparar derechos violados y como fuente de nuevos derechos ${ }^{17}$.

\section{2.- Las causas nacionales de la guerra civil}

Los primeros actos legislativos conservadores que generaron conflictos fueron: la disposición de elevar el pie de fuerza en 1859 a mil hombres para el año de 1860 que generó inquietud entre los liberales; y el decreto de este mismo año disponien-

\footnotetext{
${ }_{16}$ La Causa del Pueblo, No 3, Bogotá, 23 de mayo de 1859, p. 1; La Patria, No 48, Bogotá, 5 de junio de 1858, p. 85; El Porvenir, No 209, Bogotá, 8 de marzo de 1859, p. 426; Paula Borda, Francisco, Conversaciones con mis hijos, Bogotá, Biblioteca Banco popular, 1974, tomo I, p. 211.

17 Uribe y López Lopera, "La guerra por las soberanías...”, pp. 55-59; Parra, Aquileo, Memorias (1825-1875), Bogotá, Editorial Incunables, 1982, pp. 196-200; Pérez, Felipe, Anales de la revolución escritos según sus propios documentos, Bogotá, imprenta del Estado de Cundinamarca, 1862, p. 141.
} 
do el pago para indemnizar los bienes embargados a los rebeldes conservadores en la pasada guerra civil de 1851, cuando el entonces presidente José Hilario López expropió al jefe conservador rebelde Julio Arboleda para restablecer el orden público. Este decreto facultó al presidente Ospina (copartidario y aliado de Arboleda) para pagar la suma de $\$ 151$. 813,8 por capital y $\$ 63$. Ooo por intereses a Julio Arboleda. Para los liberales esto fue una "insultante espoliación a la república"18.

La agitación liberal fue mayor cuando el congreso aprobó la ley de elecciones el 8 de abril de 1859, la cual estableció la división de los 8 Estados de la Confederación en círculos electorales y estos en distritos ${ }^{19}$. Con esta ley se restringió el acceso a los cargos públicos regionales a los políticos liberales bolivarenses, ya que el control sobre el proceso electoral quedaba en manos de los empleados nacionales nombrados por el congreso y el presidente de la Confederación, quienes vigilaban y controlaban los listados de votantes y realizaban los escrutinios. En consecuencia, la burocracia provincial liberal fue excluida del control del evento electoral, otorgándoles ventajas a las mayorías conservadoras del congreso, lo que exacerbó la lucha en la costa caribe contra los empleados nombrados en Bogotá, constantemente acusados de fraude electoral en las localidades para perpetuar la hegemonía conservadora en el poder local y lograr el monopolio de los cargos públicos regionales y nacionales ${ }^{20}$.

${ }^{18}$ Ley (23, febrero, 1859) sobre fuerza pública nacional para el próximo año económico. Gaceta Oficial, No 2359, Bogotá, 1859, p. 121; Decreto (28 de marzo de 1859) mandando a pagar cierta deuda a Julio Arboleda. Gaceta Oficial, No 2383, Bogotá, 1859. La indignación y rechazo contra estas medidas quedan retratadas en la prensa liberal: La Causa del Pueblo, No 1, Bogotá, 10 de mayo de 1859, pp. 1-2; El Tiempo, No 229, Bogotá, 17 de mayo de 1859, p. 1.

${ }^{19}$ Ley (8, abril, 1859) de elecciones. Gaceta Oficial, No 2385, Bogotá, 1859, pp. 233-234-235. El Estado de Bolívar quedó dividido en los círculos de Cartagena, Corozal, Mompós y Barranquilla. Asimismo, se formaría un consejo electoral en el Estado de Bolívar compuesto de 9 miembros nombrados cada 2 años: 3 por el senado, 3 por la cámara y 3 por el presidente de la confederación; en cada círculo fue creada una junta electoral compuesta de 7 miembros nombrados cada 2 años por el consejo electoral y en cada distrito electoral se estableció un jurado de elecciones compuesto de 5 miembros nombrados por la junta electoral del círculo cada dos años. El consejo electoral se instalaría en la capital del Estado (Cartagena), las juntas en las cabeceras de los círculos electorales y los jurados en las cabeceras de sus distritos.

${ }_{20}$ El Porvenir, No 229, Bogotá, 17 de mayo de 1859, p. 507; El Porvenir, No 302, Bogotá, 27 de enero de 1860, p. 799; El Heraldo, órgano del partido conservador, No 16, Bogotá, 4 de agosto de 1860, p. 2; La Patria, No 29, Bogotá, 16 de enero de 1858, p. 9. Los liberales declararon: "La ley de elecciones expedida por el congreso de la Confederación en el presente año en cuanto determina el modo de elegir los senadores y representantes de los Estados, es un acto inconstitucional y revolucionario, atentatorio contra los derechos de la soberanía de los Estados de la confederación”, ver: El 
El gobierno conservador, advirtiendo las amenazas de sublevación liberal, el 30 de abril de 1859 aprobó la ley que prorrogó las leyes de presupuestos y de pie de fuerza en caso de no reunirse el congreso. La cual estableció el cobro de contribuciones por parte del ejecutivo nacional para los gastos públicos y el mantenimiento de fuerzas armadas en caso de subversión del orden general, así como el cierre de uno o más puertos de la Confederación y las medidas necesarias para asegurar las rentas de aduanas. También podía el ejecutivo trasladar provisionalmente la capital de la Confederación al lugar que dispusiera seguro mientras se restablecía el orden, acciones encaminadas a combatir una posible rebelión liberal21.

Días después el congreso aprobó la ley que organizaba la fuerza pública en la Confederación. Esta ley dispuso como deber de los Estados organizar, armar y disciplinar, cuerpos de fuerza pública municipal (milicias) al servicio del gobierno general, al cual le correspondía su inspección, reorganización, destinos, nombramientos de jefes y oficiales, y la creación de un funcionario llamado "inspector de la fuerza pública" en cada Estado. El inspector informaría al gobierno general sobre la organización y fuerza disponible en las regiones, su armamento y estado de las municiones, realizaría el llamamiento al servicio de las armas y comunicarían órdenes sin intermediación de gobernadores o alcaldes, encargándose de la ejecución de los mandatos nacionales. De esta manera, las autoridades estatales debían obedecer al inspector en cumplimiento de las leyes impuestas por el gobierno central22.

Las pretensiones de la ley sobre la fuerza pública afectaron a las élites locales al reemplazar de los mandos militares a los intermediarios regionales, dejando a los agentes nombrados por Ospina como encargados de la vigilancia y control de la milicia del Estado de Bolívar. Por otra parte, la ley nacional sobre la fuerza pública entró en contradicción con la legislación promulgada por la asamblea bolivarense,

Tiempo, No 231, Bogotá, 31 de mayo de 1859, p. 1; La Causa del Pueblo, No 2, Bogotá, 17 de mayo de 1859, pp. 1-2; El Tiempo, No 230, Bogotá, 24 de mayo de 1859, p. 1; El Tiempo, No 159, Bogotá, 19 de abril de 1859, p. 1.

${ }^{21}$ Ley (30, abril, 1859) prorrogando el término de las leyes de presupuestos y de pie de fuerza para el caso de no reunirse el congreso. Gaceta Oficial, No 2397, Bogotá, 1859, p. 306. Para el liberalismo estas acciones fueron los primeros preparativos conservadores para enfrentar una posible guerra civil, ver: El Tiempo, No 228, Bogotá, 10 de mayo de 1859, p. 1.

${ }^{22}$ Ley (12, mayo, 1859) sobre organización e inspección de la fuerza pública de los estados. Gaceta Oficial, No 2397, Bogotá, 1859, p. 306. 
comisionada para determinar los gastos militares, el pie de fuerza anual, las armas y el control sobre los cuerpos armados regionales, los cuales eran los encargados de sostener en el poder a determinadas familias de notables. Por consiguiente, la asamblea legislativa y los gobernadores, perdían uno de sus baluartes de poder en el Estado de Bolívar: la fuerza pública legítima, así como la posibilidad de nombrar jefes y oficiales sujetos a los mandatos de la burocracia regional, teniendo que aceptar funcionarios foráneos leales al gobierno central 23.

Junto con la ley sobre fuerza pública se emitió la de hacienda nacional, que creó en los Estados, distritos de hacienda regidos por los intendentes. Estos actuaban como agentes del gobierno general con las siguientes funciones: hacer cumplir las leyes y decretos nacionales; gestionar la administración, recaudo, inversión y contabilidad de los bienes, rentas y contribuciones de los negocios concernientes a los Estados y al gobierno general; asimismo, vigilar y castigar la conducta de los empleados de las oficinas de hacienda nacional en los distritos y de las demás oficinas y establecimientos dependientes del ejecutivo nacional; estaba facultado para suspender y someter a juicios a los empleados distritales, nombrar empleados para las oficinas de hacienda distrital, vigilar el recaudo de las rentas y los aportes a la tesorería general que deben hacer las administraciones locales; vigilar las cuentas de las oficinas de hacienda, aduanas y oficinas de comercio, los recaudos y pagos; así como presentar las cuentas, balances y estudios de contabilidad general, examinar las leyes, decretos y resoluciones de las legislaturas de los Estados para determinar su coherencia con las leyes y la constitución nacional; y por último, el intendente tenía la facultad de imponer multas y arrestos a los que le falten el respeto, desobedezcan o incumplan sus órdenes en los negocios de su competencia ${ }^{24}$.

La creación de funcionarios nacionales, representantes del gobierno central conservador en los Estados, generó disputas con las burocracias locales, sobre todo en aquellas regiones donde gobernaba el partido liberal (Magdalena y Santander). El rechazo en el Estado de Bolívar a estos funcionarios nombrados en Bogotá fue evidente: "Es un empleado intruso, porque le ha comido a la Nación sus mil y pico de pesos, esta cuestión interesa a todos los granadinos, pues es a nuestra costa que

\footnotetext{
23 Pérez, Felipe, “Anales de la revolución...”, p. 146; El Tiempo, No 227, Bogotá, 3 de mayo de 1859, p. 1.

${ }^{24}$ Ley (10, mayo, 1859) organizando la hacienda nacional. Gaceta Oficial, No 2402, Bogotá, 1859, pp. 328-329-330.
} 
se forma el fondo con que se le paga a este ilegítimo empleado el suelo con que se sustenta para vilipendiar los hijos de la costa" 25 . Además, los intendentes de hacienda fueron calificados como agentes del gobierno central que violaban la soberanía de los Estados interfiriendo en asuntos internos y generando conflictos con el partido contrario al gobierno general. Un ejemplo de ello fue el nombramiento del señor Navas Azuero con la doble intendencia de Magdalena y Bolívar, quien suspendió al administrador de aduanas Antonio Rodríguez Tórices y al contador Marcos Merlano por su complicidad con el ingreso de contrabando por los puertos de Santa Marta, Sabanilla y Cartagena, ante lo cual, Azuero nombró a Luciano Jaramillo para reemplazarlos, esto generó el rechazo de la "aristocracia contrabandista" que agredió al empleado nacional obligándolo a refugiarse en la casa de aduanas ${ }^{26}$.

Por último, la reforma a la justicia y la ley aclarando el artículo 49 de la constitución, establecieron que la corte suprema de la Confederación podía decidir causas civiles o criminales que involucraran extranjeros o vecinos de los Estados, dictando sentencias definitivas y actuando como instancia superior a la de los jueces de distrito. Además, la corte suprema debía decidir como última instancia las controversias sobre expropiaciones, delitos contra los altos funcionarios del Estado y anular las sentencias definitivas que pronunciaran los tribunales y jueces de los Estados que violen o desconozcan el poder de la corte suprema de justicia ${ }^{27}$.

Este conjunto de leyes promulgadas por el congreso en 1859 fueron percibidas como violatorias al orden constitucional de 1858 por parte de los sectores liberales excluidos de la participación política. En general, las leyes pretendieron el control y monopolio directo del Estado central a las elecciones, la hacienda, la fuerza pública y la justicia. Otras leyes que causaron desacuerdos y conflictos fueron las aprobadas en el contexto de la disputa política como prevención del gobierno general frente a una posible guerra. Los líderes conservadores Bartolomé Calvo, Julio Arboleda y Mariano Ospina, argumentaron que la guerra tuvo sus orígenes en las ambiciones personales de Tomás Cipriano de Mosquera, quien se separó del parti-

25 CARTA I, Hoja suelta, Barranquilla, 27 de junio de 1859, Imprenta de El correo de la costa por José María Linero.

${ }^{26}$ El Tiempo, No 226, Bogotá, 26 de abril de 1859, p. 1.

${ }_{27}^{27}$ Ley (14, mayo, 1859) aclarando el art. 49 de la constitución; Ley (15, mayo, 1859) adicional y reformatoria de la orgánica del poder judicial de la confederación. Gaceta Oficial, No 2398, Bogotá, 1859, pp. 310-311. 
do conservador al no ser elegido como candidato para la presidencia en las elecciones de 1856. Asimismo, Ospina argumentaba que la guerra se desató ante el irrespeto a los empleados nacionales, el desacato y la derogación de las leyes nacionales por las asambleas estatales dominadas por el "partido liberal radical sedicioso" que le disputaba al gobierno nacional sus atribuciones atrincherado en los Estados, los cuales, según el pacto federal debían obedecer incondicionalmente al gobierno central y a sus agentes en las regiones ${ }^{28}$.

Las contradicciones entre la legislación nacional y las leyes de los Estados que, procuraron fortalecer a los poderes regionales a través de la descentralización de las rentas, la justicia, la fuerza pública y las elecciones, fue posible debido a la formación de Estados federales en 1857 con capacidad de crear sus constituciones y nombrar a sus funcionarios sin un marco constitucional nacional, dado hasta 1858 . La carencia de un ordenamiento legal nacional dio cabida a las distintas interpretaciones sobre la soberanía de los Estados y su relación con el Estado central, justificación fundamental del conflicto. Por lo tanto, la definición de las relaciones entre los Estados con el gobierno central fue la causa principal de la guerra civil 18591862, al igual que el establecimiento del poder regional en manos de uno $\mathrm{u}$ otro partido 29 .

La agenda legislativa conservadora de 1859 provocó la resistencia de los intermediarios regionales y del partido liberal, con el propósito de mantener formas de dominio indirecto que les permitía mayor espacio de maniobra política y una intermediación que obligaba al Estado central a negociar sus atribuciones con los poderes locales. Por consiguiente, entraremos a examinar cómo fueron calificadas estas leyes nacionales en el Estado de Bolívar y el debate jurídico en torno a la soberanía de los Estados. Además, el momento prebélico se caracterizó no sólo por la organización de cuerpos armados y la provisión de recursos para la guerra, este momento parte de las disputas jurídicas entre los dos partidos políticos, los cuales buscaban la agregación de fuerzas a sus causas, disputas que se vieron representadas en constituciones, leyes, decretos y discursos que interpretaban a su manera la constitucionalidad o inconstitucionalidad de la ley, la competencia para dictar

\footnotetext{
${ }^{28} \mathrm{El} \mathrm{Heraldo}$, órgano del partido conservador, No 2, Bogotá, 28 de abril de 186o, p. 1; Quijano Otero, José María, Diario de la guerra civil de 1860 y otros sucesos políticos, Bogotá, Editorial incunables, 1982, p. 15; Arboleda, Sergio, Diario de operaciones del ejército del sur de la confederación granadina, Bogotá, Banco de la república, 1994, p. 32.

${ }_{29}$ El Heraldo, órgano del partido conservador, No 7, Bogotá, 2 de junio de 1860, p. 1.
} 
normas y la capacidad de los funcionarios públicos para emitir mandatos o prohibiciones ${ }^{30}$.

Como respuesta al conjunto de leyes nacionales emitidas por la administración conservadora de Ospina, los Estados con gobiernos liberales se valieron de su autonomía para legislar y derogar estas leyes en sus regiones (Cauca, Santander y Magdalena). Por su parte, el Estado de Bolívar inició su propia lucha armada contra el gobierno seccional conservador de Juan Antonio Calvo que pretendió implementar dichas leyes y decretos en el Estado, siendo combatidas por los notables liberales de la región. Mientras en los Estados dominados por los conservadores (Cundinamarca y Boyacá) la legislación de 1859 fue celebrada, los Estados de Antioquia y Panamá guardaban una aparente neutralidad.

\section{3.- El contexto politico regional}

En 1854 Juan José Nieto, caudillo liberal de la costa atlántica, ascendió política y socialmente después de una brillante formación intelectual autodidacta y de sus vínculos matrimoniales con las familias Cavero y Palacios, representantes de los intereses comerciales cartageneros ${ }^{31}$. La carismática personalidad y el origen social

$3^{30}$ Guerra, José Joaquín, "Estudios históricos”, tomo I, pp. 208-209. Más allá de las razones políticas y económicas partidistas para desatar la guerra civil, existieron motivaciones de índole personal entre los caudillos y jefes políticos, "La guerra se desató no por principios partidistas, lo que nos divide son odios de partido; y odios no de partido a partido sino de jefe a jefe". Ver: El Heraldo, órgano del partido conservador, No 31, Bogotá, 4 de enero de 1861, p. 1.

${ }^{31}$ En 1839 Nieto es elegido diputado a la cámara provincial de Cartagena, contaba con una amplia producción intelectual de textos políticos, históricos, literarios y geográficos sobre la costa atlántica, acercándose a las ideas liberales con la lectura de pensadores franceses. En la guerra de los supremos ganó el grado de coronel de la guardia colombiana y apoyado por la masonería inició su carrera política. En 1849 es nombrado por Obando jefe político de Cartagena, fue representante a la cámara en 1850-1852 y nombrado gobernador de Cartagena en 1851 respaldado por el general José Hilario López. Como gobernador abolió los diezmos, la esclavitud e inició la separación entre la iglesia y el Estado, medidas que polarizaron la política regional. Identificado con la facción liberal draconiana apoyó el golpe de Melo en 1854 oponiéndose al traslado de las tropas acantonadas en Cartagena por el general Mosquera, el cual ignoró su autoridad y las embarcó para sofocar el golpe militar. Su oposición a Mosquera le costó la suspensión como gobernador en 1854, en su reemplazo fue nombrado el conservador Juan Antonio Calvo en 1857 del recién creado Estado de Bolívar. Ver: Lemaitre, Eduardo, El general Nieto y su época, Bogotá, Carlos Valencia editores, 1983, pp. 19-22-35; Fals Borda, Orlando, El Presidente Nieto: Historia doble de la Costa, Bogotá, Carlos Valencia Editores, 1981, Tomo II, pp. 42A-58A-70B-71B-72B. 
humilde de Nieto, le permitió fomentar relaciones con diversos grupos de artesanos urbanos, comerciantes y trabajadores rurales de su hacienda en Alcibia. El respaldo de distintos grupos sociales lo consolidó como líder en la región caribe y representante de las ideas liberales de la costa atlántica. Sin embargo, durante su carrera política fue víctima de humillaciones raciales y clasistas por parte de familias notables conservadoras. Tildado de arribista y apodado "el mulato", sus iniciativas de progreso local fueron ignoradas, al igual que su elección como representante a la cámara nacional y la suspensión como gobernador de Cartagena en 1855, generaron odios personales que llevaron a Nieto a combatir contra los conservadores instalados en el poder regional 32 .

El nombramiento de Juan Antonio Calvo como gobernador del Estado de Bolívar en 1857, generó las primeras asonadas liberales contra el gobierno conservador en la ciudad de Mompós. Los liberales excluidos de los cargos públicos en las localidades empezaron a armarse contra las autoridades conservadoras, su objetivo era tomar los elementos de guerra del parque de armas de Mompós. Sin embargo, estos intentos esporádicos y desordenados fueron reprimidos rápidamente por la guardia municipal manejada por el prefecto conservador José María Gutiérrez de Piñerez33.

En su único informe anual a la asamblea legislativa en el año 1858, antes de ser derrocado por la rebelión liberal encabezada por Nieto, Calvo dio cuenta de la situación del Estado de Bolívar:

Las insurrecciones en Mompós en septiembre de 1857 hizo que los pobladores abandonaran sus hogares y los recursos públicos se paralizaran; esta alarma hizo necesaria la demanda de un empréstito voluntario de 25 mil pesos el cual no pudo llevarse a efecto, porque fueron tan exiguas las cantidades que se me ofrecieron, que no eran suficientes para la movilidad y subsistencia de la tropa. En el presente año de 1858 se presentaron alteraciones al orden público en los distritos de Hatillo y Loba, aparecieron partidas de hombres armados, desconociendo las autoridades, y ejerciendo actos de depredación y violencia, hasta el punto de obligar al alcalde y juez del Hatillo a huir de la cabecera del distrito. Armados con fusiles y escopetas pelearon contra 30 hombres del cuerpo de po-

\footnotetext{
32 El Liberal, No 4, Bogotá, 4 de abril de 1858, p. 3; El Porvenir, No 234, Bogotá, 3 de junio de 1859, p. 528; El Tiempo, No 235, Bogotá, 28 de junio de 1859, p. 1.

33 Sucesos de Mompós (2 de septiembre de 1857). Gaceta Oficial, No 2181, Bogotá, 1857, p. 521.
} 
licía de la Loba dejando un sublevado muerto y al comandante de la fuerza pública herido...En el presente año no se ha hecho ninguna obra para mejorar la deplorable situación en que se hallan las vías de comunicación, la carencia de buenas vías se deriva de la escasez de población y de lo reducido de nuestro comercio...A la fecha no se ha creado ni organizado la milicia del Estado, existiendo en todo el Estado, 64 hombres de tropa y 3 oficiales, antes pertenecientes a la guardia nacional ahora de la milicia del Estado divididos en Cartagena 46 y en Mompós 21 para un total de 67 hombres ${ }^{34}$.

Ante las constantes amenazas de rebeliones en las localidades, el gobierno de Calvo reunió a la asamblea constituyente para dar al Estado de Bolívar su organización administrativa. La asamblea se reunió el 15 de septiembre de 1857, de los 24 diputados, 22 eran conservadores y 2 liberales (Sebastián Romero y Pablo Hernández). El presidente de la asamblea fue el presbítero Manuel José Anaya, el vicepresidente Manuel Germán Ribón y el secretario Joaquín F. Vélez, quienes en 1860 tomarán las armas contra las tropas nietistas 35.

Los conservadores con la mayoría en la asamblea promulgaron la constitución política del Estado, nombraron a los magistrados de la corte, a los secretarios de gobierno, hacienda y tres generales para la milicia. Además, sancionaron la reforma al código penal estableciendo penas contra la trasgresión de la constitución del Estado y el irrespeto a los funcionarios públicos. Asimismo, dictaron medidas de seguridad para conservar la paz pública y expidieron un código de procedimiento en negocios criminales. El Estado fue dividido en 5 departamentos (Cartagena, Corozal, Mompós, Sabanilla y Sinú) subdivididos en distritos y estos en 21 círculos electorales, se decretó un escudo de armas y pabellón para el Estado, así como lo necesario para efectuar el censo de la población y formar la estadística estatal, también se reglamentaron los derechos de consumo y se organizó la milicia. Por último, Calvo determinó el presupuesto de rentas estatales tomadas de impuestos sobre artículos alimenticios de primera necesidad y estableció los gastos de los distintos departamentos administrativos del Estado. La asamblea terminó sus labores el

\footnotetext{
34 Mensaje del gobernador del Estado de Bolívar a la asamblea legislativa en sus sesiones ordinarias de 1858. Gaceta oficial del Estado de Bolívar, No 64, Cartagena, 1858, pp. 1-5.

35 Instalación de la asamblea constituyente y nombramiento del gobernador provisorio, gobernación del Estado de Bolívar (15, septiembre, 1857). Gaceta Oficial, No 2181, Bogotá, 1857, p. 517.
} 
30 de diciembre de 1857 después de expedir las leyes necesarias para la organización del Estado36.

Para poder hacer efectivos los actos legislativos y contar con un respaldo a su administración frente a los ataques liberales, la creación y control de la milicia estatal fue la tarea más apremiante del gobierno de Calvo. Para ello, Ospina facultó al poder ejecutivo seccional (gobernadores y prefectos) para enajenar los elementos de guerra y ponerlos a disposición del ejecutivo local en los parques de armas en las ciudades cabecera de departamento. Igualmente, dictó las recomendaciones necesarias para realizar el reclutamiento de hombres para la formación de los distintos cuerpos armados del Estado (artillería, caballería, infantería y marina), reclutamiento que también quedó en manos del ejecutivo en los distritos ${ }^{37}$.

Sin embargo, la agenda legislativa conservadora en el Estado de Bolívar fue atacada desde la promulgación de las primeras leyes sobre cobros a los derechos de aduanas en la importación de productos. Estas leyes establecieron que las actividades comerciales se debían gravar para pagar los sueldos de los funcionarios del gobierno municipal y estatal. Igualmente, el impuesto a la destilación y venta de aguardiente, causó malestar entre los liberales dedicados al comercio de este producto en el Estado. La prensa local se pronunció contra el impuesto como un exceso del gobierno local y denunció a los empleados de aduanas de complicidad con robos y contrabando en los almacenes en los diferentes puertos. Además, la facultad coactiva otorgada a los colectores de rentas para que llevaran a cabo la recaudación fue cuestionada ${ }^{3}$.

\footnotetext{
${ }_{36}$ Arboleda, Gustavo, Historia contemporánea de Colombia, desde la disolución de la antigua república de este nombre hasta el presente, Bogotá, Banco central Hipotecario, 1990, Tomo IX, pp. 171-172; La prensa liberal en Barranquilla denunció la imposición partidista de la constitución política del Estado de Bolívar por el partido conservador, en: El Progreso, periódico político de comercio y literatura, No 3, Barranquilla, 1 de noviembre de 1857, p. 2; ver también: Constitución y leyes del Estado de Bolívar expedidas en 1857, Cartagena, Imprenta de E. Hernández, 1857.

37 Ley (24, febrero, 1858) facultando al poder ejecutivo para enajenar ciertos elementos de guerra. Gaceta Oficial del Estado soberano de Bolívar, No 33, Cartagena, 1858, p. 1; Circular (11, agosto, 1858) sobre alistamiento en la milicia del Estado de Bolívar. Gaceta Oficial del Estado soberano de Bolívar, No 57, Cartagena, 1858, p. 3.

${ }_{38}^{8} \mathrm{El}$ eco de Sotavento, No 2, Corozal, 18 de agosto de 1861, p. 3; La Reacción, periódico consagrado a la política, No 8, Cartagena, 10 de agosto de 1858, pp. 1-2; Los Rabilargos, No 1, Santa Marta, 12 de enero de 1859, p. 5. Ver también: Ley (1, diciembre, 1857) sobre derechos de consumo sobre varios efectos; Ley (7, diciembre, 1857) sobre facultad coactiva de los empleados de recaudación; Ley
} 
En Cartagena la prensa liberal afirmaba que las contribuciones sobre los artículos importados son exacciones indebidas, promotoras de disgustos a los comerciantes y un descontento general que solo se puede remediar con la derogación de las leyes y el cambio de los empleados de aduanas. El 16 de marzo de 1859 un grupo de comerciantes de Cartagena, solicitó al gobernador la suspensión de los "impuestos ilegales", declarando estar en contra de las acciones armadas ya que sus intereses se verían afectados con la parálisis de sus actividades económicas 39 .

Para vigilar el cobro de las objetadas tributaciones a las mercancías importadas, en Cartagena, Calvo nombró como fiscal de distrito a Francisco Tomás Fernández, su cuñado. Los liberales declararon que los impuestos decretados por Calvo eran acciones partidistas, recolectados entre los ciudadanos que no son de la comunión política de los empleados de aduanas, y que se favorecía eximiendo del pago a los ciudadanos del mismo partido. Los reclamos en contra de las contribuciones a las mercancías de importación y los impuestos al consumo de productos locales como el aguardiente, tabaco, caucho y café, tropezaron con los funcionarios de justicia, los cuales según los liberales, no funcionaban sino para aquellos acusadores dignos de favoritismo del juez. Las trabas y exacciones al comercio e industria local fueron vistas, por la facción nietista, como una violación a la libertad individual. "El derecho a la rebelión" fue el último recurso, después de los reclamos en la prensa y en la asamblea del Estado para eliminar los impuestos ${ }^{40}$.

Según los liberales bolivarenses, las "trasgresiones conservadoras" fueron posibilitadas por las prácticas electorales que garantizaron la mayoría de este partido en la asamblea legislativa y en los cargos públicos. Los fraudes eleccionarios denunciados son diversos, entre estos: los resultados de las elecciones en Arjona, donde no hubo más de 7 electores y el cura del pueblo arregló un registro con más 700 votos. Además, la organización de los círculos electorales "estaba viciada", por ejemplo, en el círculo de Cartagena se agregaron los distritos de Turbaná y Villanueva, lugares donde los conservadores tenían la mayoría y se excluyeron de este

(9, diciembre, 1857) de impuesto sobre el aguardiente, en: "Constitución y leyes del Estado de Bolívar...", pp. 60-61-78-79-80-81-82.

39 La voz del comercio, No 3, Cartagena, 12 de junio de 1859, p. 2.

${ }^{40}$ La voz del comercio, No 2, Barranquilla, 15 de mayo de 1864, pp. 6-7-8; El Meteoro, No 1, Barranquilla, 10 de noviembre de 1858 , p. 3. 
círculo a los distritos de Bocachica, Pasacaballos y Santa Rosa, de mayoría liberal. Los conservadores también obstaculizaban las elecciones evitando la designación de jurados para distritos de mayoría liberal como Barú, donde los nombramientos de los jurados se hicieron días antes de las elecciones, sin advertir a los votantes para que fueran a sufragar quedando sin ejercer su derecho al voto. En Barranca y Calamar fueron denunciados registros de votaciones falsos; y en San Juan y Guamo algunos votos no se contaron porque favorecían a Julián Osorio (liberal). De poblaciones como San Jacinto, Carmen y Zambrano se expulsó a los liberales de sus casas para evitar que sufragaran; en Ovejas, Chinú, Ciénaga de oro, Sampues, Sabanalarga, Soledad, Baranoa, Purísima, Lorica y Corozal fueron creados los registros de elecciones a voluntad del partido conservador, los cuales a través de la coacción dominaron las elecciones y los cargos públicos ${ }^{41}$.

Las disputas alrededor de los impuestos y las elecciones exacerbaron el faccionalismo en el Estado de Bolívar. Las pugnas personales, familiares y partidistas en torno al acceso al poder a través de las elecciones para ocupar cargos públicos y controlar las rentas y la milicia estatal, fueron en un principio los elementos que generaron las adhesiones de las facciones locales al partido liberal o conservador, más que la relación ideológica que se pudiera establecer entre sus miembros 42 .

Los años de 1857 y 1858 transcurrieron entre los reclamos del partido liberal por la anulación del cobro de los "impuestos ilegales", la inclusión política en la administración del Estado y la reforma de las prácticas eleccionarias. La guerra civil local de 1859 en el Estado de Bolívar, fue promovida por los tabacaleros de El Carmen y las sabanas de Bolívar, los productores de aguardiente de Sincelejo y representantes del sector comercial de Barranquilla, Cartagena y Magangué. El popular caudillo liberal Juan José Nieto fue respaldado por grupos armados de las sabanas (Chinú, San Antero, Momil, El Carmen) y llegó al poder regional tras una campaña militar de cinco meses en Cartagena, Mompós, Corozal y Barranquilla. El estallido de la guerra regional se extendió al ámbito nacional para enfrentar las políticas "centralizantes" de Ospina, que chocaban con los intereses de las élites costeñas al imponer políticas partidistas sobre el control de pilares fundamentales para

\footnotetext{
${ }^{41}$ La Reacción, periódico consagrado a la política, No 9, Cartagena, 25 de agosto de 1858, p. 2; ver también: Ley (23, diciembre, 1857) de elecciones; Ley (31, diciembre, 1857) creando los círculos electorales. En: “Constitución y leyes del Estado de Bolívar...”, pp. 133- 155.

42 El Porvenir, No 324, Bogotá, 13 de abril de 1860, pp. 891-892; El Progreso, periódico político de comercio y literatura, No 4, Barranquilla, 15 de noviembre de 1857, p. 3 .
} 
el sostenimiento del poder local como lo eran las elecciones, la milicia y las ren$\operatorname{tas} 43$.

\section{4.- Las causas regionales de la guerra civil}

Terminadas las campañas militares en el Estado de Bolívar en diciembre de 1859, Nieto en su mensaje a la asamblea constituyente hizo un recuento de las motivaciones que llevaron a la guerra regional y al derrocamiento de Juan Antonio Calvo. Según Nieto, la causa principal que desató el levantamiento armado liberal en el Estado de Bolívar fue: la ley 15 de junio de 1857 determinando la organización del Estado. Esta ley “despojó del derecho de administrar justicia por medio de jurados, disminuyó la libertad de imprenta y llevó a la relajación del sistema electoral entregándolo a un solo partido". Para Nieto, las armas fueron la única opción ante una "oligarquía" que a través de fraudes electorales beneficiaba a sus copartidarios, ignorando los recursos pacíficos y legales para hacer las reformas planteadas por sus opositores 44 .

Dos años después, Nieto en su mensaje a la asamblea legislativa en 1861, realizó un balance sobre las motivaciones que llevaron al partido liberal a rebelarse en contra del gobierno seccional conservador. Según Nieto, la guerra regional se desató contra la pretensión de Calvo de implementar las leyes nacionales promulgadas por el congreso en 1859 en el Estado. Los liberales del Estado de Bolívar se declararon en contra de: la ley de elecciones de 1859 que, usurpó a los Estados el derecho de estatuir lo conveniente para elegir a sus representantes al congreso nacional; la ley 10 de mayo de 1859, orgánica de la hacienda nacional, que estableció como autoridad superior a los intendentes de hacienda en el Estado; la ley de 12 de mayo de 1859, sobre organización e inspección de la fuerza pública en los Estados, la cual creó inspectores con facultad de organizar y disponer de la fuerza pública

\footnotetext{
43 Fals Borda, Orlando, "El presidente Nieto...", p. 137A.

44 Mensaje del gobernador provisorio del Estado de Bolívar a la asamblea constituyente. Gaceta oficial del Estado de Bolívar, No 126, Cartagena, 1859, pp. 1-2; Ley (15, junio, 1857) que erige en Estados diversas porciones del territorio de la república, en: Corrales, Manuel Ezequiel, Efemérides y anales del Estado de Bolívar, Bogotá, Imprenta de M. Rivas y Ca, 1892, tomo IV. pp. 189-192.
} 
regional; la ley 30 de abril, prorrogando el término de las leyes de presupuesto y de pie de fuerza, para el caso de no reunirse el congreso 45.

Sin embargo, a pesar de las protestas liberales y en cumplimiento de la ley de elecciones en el Estado, se realizó el nombramiento del consejo electoral que, como esperaban los liberales, representaron solamente al partido conservador. De inmediato, Nieto presentó ante la asamblea legislativa de Bolívar la solicitud de derogación de la ley de elecciones y la inclusión del partido liberal en los cargos públicos, denunciando dicha ley como un mecanismo para perpetuar en el poder a un solo partido46.

Simultáneamente, fue nombrado como intendente nacional y visitador fiscal para el Estado de Bolívar a Pedro Navas Azuero, enviado a Cartagena como agente del gobierno de Ospina. Este funcionario pretendía combatir el contrabando realizado con la complicidad de los administradores de aduana en los puertos del caribe. Sus acciones incluyeron la destitución del administrador de aduanas en Cartagena Antonio Rodríguez Tórices y su contador Marcos Merlano, acciones que despertaron el resentimiento hacia la injerencia de un funcionario ajeno a la región nombrado en Bogotá47.

\footnotetext{
45 Mensaje del ciudadano encargado del poder ejecutivo a la asamblea legislativa. Gaceta oficial del Estado de Bolívar, No 187, Cartagena, 1861.

46 Nombramientos de los miembros de los consejos electorales. Gaceta Oficial, No 2387, Bogotá, 1859, pp. 258-264. El consejo electoral nacional del Estado de Bolívar instalado en Cartagena el 27 de mayo de 1859 nombrado por el senado, la cámara y por el presidente Ospina, tuvo como integrantes a los representantes del partido conservador del Estado: Manuel José Anaya, Enrique Grice, José Manuel Vega, José Pablo Rodríguez de la Torre, Rafael Medrano, Bernardo Capuro, Juan Antonio Gutiérrez de Piñerez, Francisco Zubiría y Senén Benedetti. En los días posteriores se eligió a los jurados de los círculos electorales; el de Cartagena fue presidido por Juan de Dios Amador, estos jurados también fueron compuestos en su mayoría por representantes de los conservadores. Ver en: Pérez, Felipe, “Anales de la revolución...”, p. 398; Nieto, Juan José, El ciudadano Juan José Nieto presidente constitucional del Estado Soberano de Bolívar, general en jefe del $4^{\circ}$ ejército de los Estados Unidos de Colombia. Bosquejo histórico de la revolución que rejeneró al Estado de Bolívar, Cartagena, Imprenta Ruiz e hijo, 1862, p. 4.

47 Arboleda, Gustavo, "Historia contemporánea de Colombia...", Tomo X, pp. 396-397. En Santa Marta los liberales también se pronunciaron en contra de la imposición de funcionarios nombrados en Bogotá por Ospina y declararon como enemigos de los intereses locales a los intendentes, visitadores fiscales, comandantes de resguardo, administradores de rentas, contadores de aduana y cualquier otro funcionario que se inmiscuya en los asuntos internos del Estado. Ver en: El Camastrón, No 1, Santa Marta, 15 de enero de 1860, p. 2; Gaceta Oficial del Estado federal del Magdalena, No 7, Santa Marta, 1858, p. 2.
} 
Los reclamos realizados por Nieto ante la asamblea legislativa en contra de la ejecución de las leyes nacionales en el Estado de Bolívar fueron ignorados. Ante la negativa, Nieto inició el plan "regenerador" con Juan Antonio de la Espriella y el comandante Manuel Pereira Plata de Corozal. El objetivo de la regeneración era llevar a cabo una "revolución" para recuperar el poder en el Estado. El plan fue comunicado a sus compañeros de partido de confianza para formar la "junta directiva regeneradora”. Los convocados fueron: Eloi Porto, Sebastián Elguedo, Ramón Guerra y Antonio González Carazo. Esta junta inició sesiones secretamente y nombró a los encargados de recaudar los fondos para ejecutar el plan de batalla, los cuales fueron: Felipe S. Paz, Simón Gutiérrez de Piñerez, Inocencio Galindo, Andrés Santodomingo Vila, Luis Montes Ucros, José Gavino Núñez (artesano)48.

La junta regeneradora acordó que Nieto realizara una gira por el Estado en busca de apoyo y recursos. Como resultado, en Sabanalarga, se contó con el respaldo de J. Antonio Torrenegra y Celso de la Puente; en Barranquilla, Rodrigo Pantoja, Celedón Pérez, Tomás Freile, Silverio Henríquez, Vicente Palacio y Arístides Voigt se adhirieron a la causa; en Santa Marta, no hubo acogida; en Ciénaga, Francisco Labarcés; en San Antero, Sebastián Elguedo y Manuel Martínez apoyaron a Nieto con el envío de hombres y recursos a Cartagena. Por otra parte, con la colaboración del cabo José de las Nieves León y otros individuos de tropa encargados de custodiar el parque de armas en Cartagena, se planeó la toma del cuartel para proveer de armas a las tropas regeneradoras. Sin embargo, el primer intento de la ocupación del cuartel fue abandonado debido a las sospechas que levantó la movilización de Elguedo a San Antero para traer hombres y armas a Cartagena. Ante la vigilancia constante de los conservadores, Nieto decidió ejecutar un nuevo plan con una junta más discreta, compuesta por Juan Antonio de la Espriella, Antonio González Carazo y José Araujo. La nueva junta regeneradora contó con el apoyo del teniente Cruz Díaz, nombró a Nieto caudillo del movimiento y comisionó a González Carazo para comprometer a los notables de las localidades y conseguir recursos para ejecutar el plan revolucionario en Tolú, Sincelejo, Corozal, Chinú, Carmen, Magangué, Mompós y Barranquilla. La comisión logró movilizar a los "patriotas de

${ }^{48}$ Nieto, Juan José, “El ciudadano...”, p. 5; El Porvenir, No 253, Bogotá, 9 de agosto de 1859, p. 603. 
Chinú”, integrándose a la junta Manuel Mendoza y Antonio Castillo, y en Cartagena Ramón Santodomingo Vila, los cuales esperaron en Chinú el llamado a las armas49.

Para sondear a la opinión pública sobre un posible levantamiento armado contra Calvo, el 3 de julio de 1859, Nieto convocó a los cartageneros a una "junta patriótica" en el palacio municipal, con el fin de discutir "la situación peligrosa que confrontaba la república como consecuencia de algunas leyes inconstitucionales expedidas por el congreso, y adoptar las medidas que fuesen convenientes." Calvo en cumplimiento con una gira por el Estado se encontraba en Mompós cuando recibió la noticia de la reunión de la junta patriótica. De inmediato, ordenó atrincherar sus tropas en la torre del edificio San Juan de Dios y dispuso la formación de milicias en las ciudades cabecera de departamento temiendo un levantamiento armado. La reunión terminó sin contratiempos y tanto los asistentes como las tropas de Calvo se retiraron sin riñas ${ }^{\circ}$.

Los siguientes días después de la reunión de la junta patriótica trascurrieron, para el gobierno de Calvo, a la expectativa del levantamiento liberal. Las hojas sueltas publicadas en Cartagena por los liberales llamando a las armas a sus partidarios, las noticias de apoyo a la rebelión desde varias ciudades del Estado y el envío de comisiones a Barú, Pasacaballos y Santa Rosa para transportar hombres hacia Cartagena, prendió las alarmas sobre la inminente sublevación liberal. Nieto, Carazo y de la Espriella, actuaron como voceros del liberalismo protestando contra las "leyes inconstitucionales" del congreso, contra los "impuestos ilegales" y contra los "abusos del gobernador Calvo" para perpetuarse en el poder51.

La junta regeneradora fijó la fecha del levantamiento armado para el 26 de julio, hasta el momento, contaban con algunas armas depositadas en la casa de Jo-

49 Nieto, Juan José, “El ciudadano...”, p. 9.

$5^{\circ}$ Arboleda, Gustavo, "Historia contemporánea de Colombia...", Tomo X, p. 399; El 29 de julio Calvo llamó a las armas a los conservadores del Estado y nombró sus candidatos para el congreso nacional. Para senadores: general Juan Antonio Gutiérrez de Piñerez, general Joaquín Posada Gutiérrez, Manuel María Anaya, Manuel Narciso Jiménez, Antonio Rodríguez Tórices, Francisco de Subiría. Para representantes: Manuel Salvador Rodríguez, Henrique Grice, Antonio María Merlano, Demetrio Porras, Manuel Gómez Pernett, Idelfonso Macías, ver: El Porvenir, No 260, Bogotá, 2 de septiembre de 1859, p. 632.

${ }^{51}$ La noche del primero de julio los conservadores se reunieron en la casa del señor Bernardo Capurro, a la cual acudieron los generales Vicente González y Juan Antonio Gutiérrez de Piñerez; comprometiéndose estar dispuestos a tomar las armas para reprimir cualquier tentativa contra el orden público. El Porvenir, No 249, Bogotá, 26 de julio de 1859, p. 587. 
sé Araujo y ciento cincuenta pesos donados por Andrés Santodomingo Vila. La noche anterior (25 de julio), los liberales se reunieron acaudillados por Eloi Porto, Antonio González Carazo, Ramón Guerra, Federico Capela y Sebastián Elguedo a las afueras de la muralla de Santo Domingo. En complicidad con el cabo Nieves León, a la una de la madrugada del día 26 de julio después de la fiesta religiosa en honor a la madre de María santísima, los rebeldes aprovecharon la entrada de la banda de músicos al cuartel para asaltarlo. Como resultado, tomaron cuatro piezas de batalla y más de trecientos fusiles, liberaron a los presos y formaron en armas una tropa de 200 voluntarios repartidos en piquetes en diferentes puntos de la ciudad. El alcalde de Cartagena fue arrestado, el prefecto José María Pasos y los demás funcionarios conservadores huyeron hacia Calamar, pocas horas después del asalto Nieto se proclamó jefe provisorio del Estado, Carazo se encargó de la prefectura y su hermano Manuel G. Carazo de la jefatura de las armas, de la Espriella fue nombrado secretario general de gobierno y Araujo secretario de hacienda52.

Tomada Cartagena, Ramón Guerra partió para Chinú con la noticia de la sublevación, allí se nombró como prefecto a Ramón Santodomingo Vila y como comandante general de las fuerzas de las sabanas al coronel Manuel Pereira Plata. De inmediato, Ignacio Guerra y Andrés Santodomingo Vila iniciaron el plan de batalla para asaltar los principales bastiones conservadores del Estado: Mompós y Corozal. En Lorica, Manuel Martínez ocupó el cuartel militar, nombró como prefecto a Benjamín Noguera y encargó la administración de la ciudad a José y Francisco Corrales; en Ciénaga de Oro, Manuel Laza Grau y Lope Nieto (hijo de Juan José Nieto) se sumaron a la rebelión. La ocupación del cuartel militar de Cartagena el 26 de julio significó, para los liberales, la ejecución de la primera parte de su plan de batalla, así obtuvieron las armas para movilizar a sus tropas e iniciaron la sustitución de los conservadores de los cargos públicos53.

\footnotetext{
${ }^{2}$ Nieto, Juan José, “El ciudadano...”, p. 11; "La regeneración” en el Estado de Bolívar fue vista por Ospina como un plan de guerra que se extendería con el ataque de Nieto a los otros Estados con gobiernos conservadores y cuando "las huestes revolucionarias hayan tomado consistencia, y sus caudillos estén unidos en el pensamiento que les es común, entonces arrojarán el guante al gobierno general, que, reducido solo a la capital y la Sabana, tendrá que lidiar con desventaja y en un campo circunscrito, estrecho, funesto quizá al esfuerzo de las armas.” Ver: El Porvenir, No 259, Bogotá, 30 de agosto de 1859, p. 628.

53 Nieto, Juan José, “El ciudadano...”, p. 13; El Porvenir, No 258, Bogotá, 25 de agosto de 1859, p. 623 .
} 
En el acta del pronunciamiento liberal del 26 de julio la junta regeneradora resolvió: desconocer a las autoridades políticas que actualmente están al servicio del Estado; nombrar a Juan José Nieto gobernador provisorio del Estado de Bolívar con el poder para organizar transitoriamente el gobierno, guardando la constitución y leyes de la Confederación, y con la facultad de nombrar quien lo reemplace en sus faltas temporales; declarar la intención de permanecer unido a la Confederación y devolver al pueblo el derecho de gobernarse por medio de corporaciones locales, de las cuales fueron privados; modificar el sistema fiscal ajustándolo a los intereses de los industriales; acabar con las actuales restricciones a las garantías individuales; mejorar el ramo judicial para combatir los ataques a la propiedad y seguridad personal; verificar la reunión de la asamblea constituyente tan pronto como la mayoría de los pueblos se hayan adherido a la regeneración 54 .

Después del pronunciamiento, Nieto comunicó al intendente de hacienda, al presidente del consejo electoral, al protonotario apostólico, al secretario de gobierno de la confederación y al procurador nacional, el cambio de gobierno consecuencia del "movimiento regenerador", afirmando que, este era un movimiento enteramente local que debía ser resuelto sin intervención del gobierno general. Por tanto, Nieto declaró su obediencia a la constitución nacional de 1858, a las leyes de la Confederación y el libre ejercicio de las funciones de los agentes del gobierno general en el Estado de Bolívar55.

La guerra regional en el Estado de Bolívar iniciada el 26 de julio de 1859, terminó el 9 de diciembre del mismo año con el asalto a Barranquilla, después de cuatro meses y catorce días de campañas militares en que los liberales se tomaron el poder en el Estado. Las acciones tomadas por Nieto para enfrentar a los conservadores incluyeron: exigir la colaboración económica de todos los habitantes del Estado y el alistamiento en la milicia de los hombres entre dieciocho y cincuenta

\footnotetext{
54 Pérez, Felipe, “Anales de la revolución...”, p. 233; Arboleda, Gustavo, "Historia contemporánea de Colombia...”, Tomo X, p. 402. Algunas localidades emitieron actas a favor de la junta regeneradora, ver: Acta de la villa de Lorica, cabecera del departamento del Sinú. "Dispuestos a tomar las armas en defensa del gobierno actual”. Gaceta oficial del Estado de Bolívar, No 110, Cartagena, 1859, p. 1; Acta de los vecinos de la Villa del Carmen; Pronunciamiento de Momil. Gaceta oficial del Estado de Bolívar, No 114, Cartagena, 1859, p. 1; Acta de los vecinos de Sincelejo adhiriéndose al pronunciamiento que tuvo lugar en la capital del Estado el 26 de julio último. Gaceta oficial del Estado de Bolívar, No 115, Cartagena, 1859, p. 1.

55 Nota (26, julio, 1859) dirigida al señor intendente de hacienda del Estado de Bolívar. Gaceta Oficial, No 2422, Bogotá, 1859, p. 457.
} 
años; reestructurar la administración pública creando los departamentos del Carmen, Magangué y Sabanalarga. Además, nombró nuevos magistrados para la corte superior, jueces parroquiales, procurador del Estado, presidente del instituto Boliviano, prefectos de departamentos, alcaldes, instaló nuevos cabildos en los distritos, reemplazó las juntas electorales, nombró nuevo administrador de hacienda para Cartagena y mandó recoger las armas en manos de particulares. Asimismo, el 16 de diciembre Nieto reunió a la asamblea constituyente, llevó a cabo las elecciones y el 12 de enero de 1860 fue sancionada la nueva constitución del Estado, nombrándose presidente a Nieto con el grado de general de las milicias 56 .

\section{5.- Los preparativos para la guerra civil}

Propinado el golpe de cuartel por Nieto, el intendente de Bolívar Navas Azuero se reunió en la casa de la aduana en Cartagena con miembros del partido conservador para iniciar la "restauración" del gobierno de Calvo. Sus acciones contra la "regeneración liberal" incluyeron: conceder licencias a sus empleados y armarlos para capturar a Antonio González Carazo, además de realizar el llamado a las armas a los habitantes del Estado en defensa del gobierno depuesto. En consecuencia, Nieto ordenó arrestar y destituir del cargo de intendente a Navas Azuero, exigiendo al gobierno central la neutralidad de sus empleados, los cuales no debía inmiscuirse en los asuntos locales57.

Desde la cárcel, el 15 de agosto de 1859, Navas Azuero decretó el cierre de los puertos de Cartagena y Sabanilla, y el nombramiento del inspector de la fuerza pública del Estado para restablecer el orden público considerando que:

\footnotetext{
${ }^{56}$ Decreto (19, julio, 1859) declarando en asamblea el territorio del Estado de Bolívar; Decreto reestructurando la administración pública; Decreto (30, julio, 1859) mandando recoger las armas del gobierno que estén en poder de particulares. Gaceta oficial del Estado de Bolívar, No 110, Cartagena, 1859, pp. 1-2.

57 Pérez, Felipe, “Anales de la revolución...”, pp. 225-226-231; Nota (17, agosto, 1859) comunicando que el intendente de hacienda está en prisión y que el parque del Estado continua en manos de los facciosos, que del parque se extraen elementos de guerra, que el resguardo ha sido desarmado pero no han inquietado a esta oficina ni a sus empleados. Al señor secretario de gobierno y guerra de la confederación. Gaceta Oficial, No 2427, Bogotá, 1859, p. 478.
} 
La facción que se rebeló el 26 de julio aunque le ofreció garantías a los empleados e intereses de la confederación, faltó esa promesa ocupando ayer con fuerza armada los edificios y oficinas nacionales, el parque y almacenes, disponiendo de los bienes de la confederación; reduciendo a prisión en un cuartel al intendente sin respetar al representante de la confederación y a la autoridad que a su nombre ejerce legalmente; que subvertido el orden general y conspirando contra el gobierno nacional, decreta: se nombra al sargento mayor Lorenzo Indaburu como inspector de la fuerza pública de la confederación para restablecer el orden; todos los jefes y oficiales del ejército permanente de la confederación deben presentarse ante estos agentes para prestar sus servicios; todos los que tengan elementos de guerra pertenecientes a la confederación los deben entregar a las autoridades legítimas para prestarlos a su servicio; se nombra a Manuel del Rio comisionado como intendente de hacienda mientras Pedro Navas Azuero este en prisión ${ }^{8}$.

La intervención de los empleados nacionales en la contienda partidista por el poder en el Estado de Bolívar, generó un extenso debate jurídico sobre los alcances de la soberanía nacional en relación con la soberanía de los Estados federales creados en 1857. El general Mosquera actuó como vocero del liberalismo ante el gobierno de Ospina enviando una nota de protesta contra las disposiciones hechas por el intendente de Bolívar como contrarias a la constitución de 1858 y violatorias a la soberanía de los Estados en los siguientes términos: primero, según Mosquera, el decreto emitido por el intendente Navas Azuero que dispone la creación de la "guardia nacional de la confederación" es inconstitucional, ya que dicho cuerpo armado no existe, debido a que la constitución nacional sólo reconoció la existencia de las milicias a cargo de los Estados en la atribución quinta del artículo 43 y del ejército y marina de guerra a cargo del gobierno general en la atribución quinta del

\footnotetext{
${ }^{8} \mathrm{El}$ intendente de los distritos de hacienda del Magdalena y Bolívar, considerando: que el orden público de la confederación ha sido subvertido en el distrito de hacienda de Bolívar y haciendo uso de sus facultades conferidas por el poder ejecutivo nacional en la ley 30 de abril y 11 de 7 de mayo de 1859, decreta: cerrar los puertos de Cartagena y Sabanilla hasta restablecer el orden público y los empleados de aduanas puedan ejercer sus funciones; todo tráfico mercantil con el exterior que se haga por estos puertos deshabilitados quedan sujetos a las penas por contrabando; las importaciones y exportaciones se harán por los puertos de Santa Marta y Riohacha; comunicar esta medida a los cuerpos consulares de Cartagena, Barranquilla y Sabanilla para prevenir a los capitanes de los buques extranjeros. Decreto (15, agosto, 1859) declarando cerrados los puertos de Cartagena y Sabanilla. Gaceta Oficial, No 2426, Bogotá, 1859, p. 474. El asalto a las oficinas, edificios, parques y almacenes nacionales y el arresto del intendente de hacienda por los "regeneradores", llevó al intendente Navas Azuero a declarar alterado el orden público llamando a los prefectos y alcaldes a enviar contingentes de milicias a Mompós a su disposición. Decreto (23 agosto 1859) sobre orden público general. Gaceta Oficial, No 2427, Bogotá, 1859, p. 477.
} 
artículo 15; segundo, la ley 12 de mayo de 1859, declarada inconstitucional por el Estado de Bolívar, dispone la inspección y uso de las milicias por el gobierno general a través del agente nacional denominado "inspector de la fuerza pública", sin embargo, según Mosquera, sólo el presidente de la Confederación puede pedir a los gobernadores de los Estados, en igualdad proporcional, los contingentes de milicias a su servicio cuando el orden público nacional lo requiera, correspondiendo exclusivamente al gobernador del Estado mantener el orden público seccional, la seguridad interior y el control de las milicias para evitar actos que atenten contra la soberanía del Estado. Por consiguiente, los intendentes e inspectores de la fuerza pública son "agentes" del gobierno general en los Estados pero no cuentan con autoridad superior al poder ejecutivo seccional (gobernadores, prefectos y alcaldes) como lo disponen los artículos 10 y 45 de la constitución. Según estas reclamaciones Mosquera expresó: "Con tal objeto me dirijo al presidente de la confederación para que, como encargado de hacer cumplir las leyes y velar en la conservación del orden general, no permita que sus agentes salgan de la esfera de sus funciones. Debo hacer notar a usted que los encargados directamente y especialmente de hacer que se cumpla y ejecute en los estados la constitución federal son las autoridades de ellos, y especialmente los gobernadores59."

El secretario de gobierno y guerra de la Confederación, Miguel Antonio Sanclemente, contestó a Mosquera de la siguiente manera: primero, la denominación "agente" o "representante" dada a los intendentes significa lo mismo según el artículo 45 de la constitución, el nombre asignado a estos funcionarios públicos nacionales no los despoja de sus atribuciones, las cuales según el artículo 31 de la ley 19 de mayo, deben ejecutar todas las disposiciones del gobierno nacional como sus representantes en los Estados. Segundo, según el artículo 15 de la constitución nacional, corresponde al ejecutivo nacional organizar, distribuir, dirigir y sostener la fuerza pública al servicio de la Confederación, que con arreglo a la ley 23 de febrero sobre fuerza pública nacional, los cuerpos armados formados en los Estados quedan a disposición del presidente de la Confederación para ser organizados y divididos como lo juzgue necesario y conveniente, autorizando a sus representantes en los Estados para disponer de dichos cuerpos armados, llámese ejército permanente o guardia nacional. Esto no atenta contra la organización de las milicias ya que es-

59 Nota no. 32 del gobernador del Estado soberano del Cauca, al señor secretario de Estado en el despacho de gobierno y guerra. Gaceta Oficial, No 2434, Bogotá, 1859, p. 505. 
tas también forman parte de las fuerzas de la Confederación. Tercero, según Ospina, no es exclusivo del ejecutivo seccional la conservación del orden público y el control de la milicia en los Estados, ya que las atribuciones al ejecutivo general, (atribución veinte del artículo 43) incluyen hacer cumplir las leyes y la constitución nacional en los Estados, y le asigna al presidente de la Confederación la capacidad de emplear la fuerza pública en caso de perturbación del orden público por desobediencia a la constitución, según el artículo 15 inciso cuarto60.

Mosquera contestó a Ospina con una nueva nota de protesta afirmando estar cumpliendo con las leyes y la constitución nacional según el artículo 10 sobre las atribuciones a las autoridades estatales. Además, según Mosquera, el artículo 45 citado por Ospina, no le otorgó al presidente de la Confederación la facultad de crear a su voluntad agentes en los Estados. Asimismo, le recordó al gobierno general que, según los artículos 10 y 45 de la constitución nacional, no le corresponde al presidente de la Confederación hacer cumplir las leyes y la constitución en los Estados, esta atribución es propia de las autoridades estatales. Por consiguiente, la creación de agentes y empleados por el gobierno nacional para ejecutar y hacer cumplir las leyes, por encima de la autoridad del ejecutivo seccional, es una violación a la soberanía de los Estados. Esta violación se manifestó en las leyes nacionales de 1859, las cuales según el general Mosquera, responden a intereses partidistas, al igual que el nombramiento de los empleados nacionales en los Estados. Para terminar, Mosquera explicó: que a los intendentes sólo les corresponde encargarse de asuntos económicos, sin autoridad para intervenir en negocios políticos, civiles o militares, los cuales son exclusivos del gobernador del Estado quien dispone todo lo relacionado al orden social, político y militar ${ }^{61}$.

Las reclamaciones fueron rechazadas por Ospina que determinó: según el artículo 21 de la ley 10 de mayo en concordancia con el artículo 45 de la constitución nacional, los intendentes tienen la obligación de hacer cumplir las leyes y mandatos del gobierno general en los Estados, ejercer las funciones y deberes que le imponga el presidente de la Confederación sin comunicar sus misiones y órdenes especiales a los gobernadores; en lo relativo a la milicia el poder ejecutivo nacional

\footnotetext{
60 Contestación, no. 19 (28, octubre, 1859) poder ejecutivo nacional, secretaria de estado del despacho de gobierno y guerra, Miguel Antonio Sanclemente al señor gobernador del Estado del Cauca. Gaceta Oficial, No 2434, Bogotá, 1859, p. 506.

${ }^{61}$ Nota, no. 34 del gobernador del Estado del Cauca, al señor secretario de Estado en el despacho de gobierno y guerra de la confederación. Gaceta Oficial, No 2441, Bogotá, 1859, pp. 533-534.
} 
obrará según la ley 12 de mayo de 1859, y frente a la denuncia de Mosquera de inconstitucionalidad y partidismo de las leyes de 1859, Ospina contestó: “...que a ninguno en la república le es permitido calificar de inconstitucionales las leyes expedidas por el congreso nacional, y mucho menos a los gobernadores, que en vez de propender a despopularizarlas, tiene el imperioso deber de cumplirlas y hacerlas cumplir mientras no sean derogadas ${ }^{62} . "$

Siguiendo la interpretación que Mosquera hizo de la constitución nacional sobre las funciones de los empleados nacionales, la relación entre el gobierno general y los Estados, y el control político, económico y militar que se debía establecer en las jurisdicciones estatales, Nieto determinó que, el intendente de hacienda Navas Azuero violó la soberanía del Estado de Bolívar, la constitución de 1858 y usurpó su autoridad como gobernador. El arresto y destitución del intendente de Bolívar por pretender movilizar cuerpos armados en el Estado en contra del gobierno provisorio, y por el cierre de los puertos de Cartagena y Sabanilla para intentar socavar las bases económicas de la "regeneración liberal", fueron percibidos por Nieto como un ataque partidista del gobierno de Ospina en respaldo a su aliado, el depuesto gobernador Calvo ${ }^{63}$.

El nuevo intendente Luciano Jaramillo, nombrado desde la cárcel por Navas Azuero, fue arrestado junto con Manuel del Rio (comisionado de hacienda) acusados de delitos contra el Estado y de conspirar contra el gobierno provisorio. En consecuencia, Nieto se autoproclamó intendente de hacienda de los Estados de Bolívar y Magdalena, acción que despertó el rechazo de Ospina, quien a través de la secretaría de hacienda nacional acusó a Nieto de usurpar la autoridad del representante del gobierno nacional, ya que sólo el presidente de la Confederación y la corte suprema de justicia podían nombrar y remover de sus puestos a los empleados nacionales 64 .

${ }^{62}$ Contestación, no. 12 (6, diciembre, 1859) al señor gobernador del Estado del Cauca, poder ejecutivo nacional, secretaria de Estado del despacho de gobierno y guerra. Gaceta Oficial, No 2441, Bogotá, 1859, p. 534.

63 La Nueva Alianza, No 5, Cartagena, 25 de noviembre de 1860, p. 3.

64 Decreto (19, diciembre, 1859) por el cual Nieto se encarga del puesto de intendente; Resolución (14, enero, 1860); Informes de los principales empleados fiscales del distrito de hacienda de Bolívar, y resolución del poder ejecutivo nacional declarando nulos los actos del titulado intendente de dicho 
Estos conflictos entre los empleados del gobierno nacional y las burocracias regionales, y al interior de los Estados entre los partidos liberal y conservador por monopolizar los cargos públicos, llevaron a las diferentes legislaturas regionales a reclamar la derogación de las leyes nacionales de 1859 como última medida para evitar una guerra civil nacional. Las leyes declaradas inconstitucionales por las legislaturas fueron: $1^{\circ}$. La ley 8 de abril, sobre elecciones; $2^{\circ}$. La ley 30 de abril, prorrogando el término de las leyes de presupuesto y de pie de fuerza pública para el caso de no reunirse el congreso; $3^{\circ}$. La ley de 12 de mayo, sobre organización e inspección de la fuerza pública en los Estados; $4^{\circ}$. La ley 14 de mayo, aclarando el artículo 49 de la constitución; $5^{\circ}$. La ley 15 de mayo, adicional y reformatoria de la orgánica del poder judicial de la confederación. Las legislaturas del Cauca, Bolívar, Magdalena y Santander exigieron suprimir las cinco leyes "inconstitucionales y violatorias a la soberanía de los Estados”. Panamá solicitó la derogatoria de las leyes $1^{\mathrm{o}}, 3^{\mathrm{o}}$ y $4^{\mathrm{o}}$ como contrarias al sistema federal sin considerarlas inconstitucionales. Antioquia instó la revocatoria de las leyes $3^{\circ}$ y $4^{\circ}$ como contrarias a la constitución. Por otra parte, Boyacá y Cundinamarca pidieron que se conserven todas estas leyes como constitucionales y convenientes para la Confederación. La resolución ante el reclamo de las legislaturas fue firmada por Pastor Ospina, Vicente Cárdenas, Juan Uribe, Manuel José González y Juan Narváez, negando la revocatoria de las leyes en los siguientes términos: "La legislación sobre elecciones de senadores y representantes de la confederación corresponde exclusivamente al congreso conforme al inciso $1^{\mathrm{o}}$, art 14, 15 y 29 de la constitución, en consecuencia, la ley 8 de abril de 1859 es constitucional y no vulnera el derecho de los estados. En cuanto a las demás leyes estas no son contrarias a la constitución federal ni violatorias del derecho de los estados $65 . "$

Además, en su informe anual al congreso Ospina defendió las leyes nacionales de 1859 a través de una compleja exposición jurídica y advirtió a las legislaturas estatales: "Solicitar la derogación de una ley es un acto inocente sobre el cual no puede recaer ningún género de censura; el calificar de inconstitucional una ley, sin derecho para ello, es un acto subversivo...los que pretenden conmover al país, quie-

\footnotetext{
distrito de hacienda, señor Juan José Nieto (Cartagena 20, diciembre, 1859). Gaceta Oficial, No 2450, Bogotá, 1860, pp. 33-34.

65 Informe no. 37 (12, marzo, 1860) de las comisiones de ambas cámaras sobre las peticiones de las legislaturas de los Estados, congreso nacional, secretaría de la cámara del senado. Gaceta Oficial, No 2483, Bogotá, 1860, p. 206.
} 
ren presentar al gobierno general como una entidad extraña a los estados, como una potencia en lucha con todas las secciones, para escitar el espíritu local y producir la contienda66."

En cuanto a la contienda partidista en el Estado de Bolívar, Ospina declaró el fin de la lucha armada local con la derrota de las "fuerzas del orden legal" y el establecimiento de una "autoridad dictatorial". Para Ospina, la insurrección liberal, en un principio local, trascendió a nivel nacional cuando "los insurrectos" acaudillados por Nieto ocuparon el rio Magdalena, Cauca y el Canal del Dique con buques armados en guerra, atacaron a los empleados nacionales y asaltaron las oficinas y edificios de la Confederación. Estas circunstancias, llevaron al presidente a declarar el estado de guerra en la Confederación ante "el plan de sublevación general contra el orden constitucional establecido", y por causa del levantamiento a mano armada en el Estado de Bolívar, que provocó la ruptura de las relaciones de este Estado con el gobierno general ${ }^{67}$.

Ante la derrota militar de Calvo y el afianzamiento político de Nieto, el presidente Ospina envió al general en jefe de los ejércitos de la Confederación Pedro Alcántara Herrán para negociar el restablecimiento de las relaciones entre el gobierno general y el Estado de Bolívar. Al mismo tiempo, Ospina envió tropas a Santander y Magdalena preparando una invasión contra Nieto. Como resultado de la visita de Herrán a Cartagena, el 22 de febrero de 1860 se firmó el convenio HerránNieto aprobado por Ospina el 26 de marzo del mismo año. Sin embargo, celebrado este convenio Ospina siguió auxiliando los esfuerzos militares de los conservadores

\footnotetext{
${ }^{66}$ Informe del presidente de la confederación granadina al congreso nacional de 1860. Gaceta Oficial, No 2452, Bogotá, 186o, pp. 43-44-45. Para Ospina, la ley 30 de abril tenía su respaldo en la atribución primera y octava al congreso del artículo 29 de la constitución nacional; las leyes 14 y 18 de abril fueron sustentadas según la atribución novena del artículo 49; la ley 12 de mayo fue defendida según las atribuciones quinta y vigésima del artículo 43; la creación de agentes en los Estados fue respaldada por el artículo 45, al igual que el control de la milicia por la atribución quinta del artículo 15 de la constitución nacional. Por último, la ley de elecciones fue justificada por la inexistencia de una ley nacional que organice y regule el procedimiento eleccionario.

67 Alocución del presidente de la confederación a los granadinos. Gaceta Oficial, No 2532, Bogotá, 1860, p. 433. Decreto (3, septiembre, 1859) declarando en estado de guerra la confederación; Decreto $(5$, septiembre, 1859$)$ elevando el pie de guerra la fuera pública. Gaceta Oficial, No 2426, Bogotá, 1859, p. 473.
} 
por recuperar el poder en el Estado de Bolívar, lo que más tarde llevó a la separación definitiva del Estado de la Confederación ${ }^{68}$.

Para restablecer las relaciones entre el gobierno general y el Estado de Bolívar, Nieto y Herrán acordaron: declarar el enfrentamiento armado en el Estado como una guerra local que no involucró al gobierno general; Nieto se comprometió a entregar la intendencia de hacienda a Manuel del Rio, restablecer a los representantes del gobierno general en sus empleos, desarmar los buques de guerra, evacuar militarmente el rio Magdalena y devolver el parque de armas de Cartagena. Por su parte, Herrán declaró abiertos los puertos de Cartagena y Sabanilla, y reconoció a Nieto como autoridad legítima en el Estado de Bolívar69.

Pastor Ospina y Julio Arboleda manifestaron su desaprobación al convenio firmado en Cartagena por Herrán como representante del partido conservador, argumentando que los liberales serían los únicos responsables del derramamiento de sangre en la Confederación al desobedecer la legislación nacional. Herrán fue duramente criticado, acusado de ser cómplice de Nieto, amigo de los liberales y estar influenciado políticamente por su suegro Mosquera. El convenio fue calificado de indecoroso para la Nación y sospechoso de favorecer al liberalismo de la costa70.

68 Nota (13, diciembre, 1859) dirigida al secretario de Estado del despacho de guerra y gobierno, participándole el término de la guerra en el Estado, e indicando los medios de restablecer la buena inteligencia entre el Estado y la confederación. Gaceta oficial del Estado de Bolívar, No 126, Cartagena, 1859 , p. 4. En esta nota Nieto declaró que, para normalizar las relaciones con el gobierno general, Ospina debía: revocar la declaratoria de guerra en la Confederación, abrir los puertos de Cartagena y Sabanilla, reducir el pie de fuerza y no enviar soldados contra el gobierno provisorio de Nieto, nombrar nuevos agentes nacionales en el Estado ajenos a los partidos, reconocer legalmente el actual gobierno en el Estado de Bolívar respetando sus leyes y autoridades.

69 Resolución (26, marzo, 1860) del poder ejecutivo sobre los arreglos celebrados por el ciudadano general Pedro Alcántara Herrán general en jefe del ejército de la confederación, con el gobernador del Estado de Bolívar. Gaceta Oficial, No 2496, Bogotá, 1860, p. 262. El acuerdo Nieto-Herrán dividió a los conservadores alrededor de los candidatos para las elecciones de 1861 entre Julio Arboleda y Pedro A. Herrán. El primero, partidario de someter a los liberales a través de las armas, dirigió la facción "reaccionaria". El segundo, planteó una salida negociada al conflicto para evitar la guerra civil, criticó las acciones legales de Ospina y la dirección que le daba a la disputa con el liberalismo, esta facción fue criticada por los "reaccionarios" de simpatizar con los liberales y con las ideas federales, ver: El Heraldo, órgano del partido conservador, No 22, Bogotá, 30 de octubre de 186o, p. 1.

$7^{7}$ El Heraldo, órgano del partido conservador, No 1, Bogotá, 21 de abril de 1860, p. 1; El Porvenir, No 318, Bogotá, 23 de marzo de 1860, p. 868; En un artículo titulado "Mi opinión” Herrán defendió sus acuerdos con Nieto y hace las siguientes recomendaciones a Ospina para detener la lucha arma- 
Sin embargo, el conflicto nacional continuó alrededor de las leyes de 1859. En consecuencia, Nieto convocó el 31 de mayo de 1860 a la legislatura de Bolívar a sesiones extraordinarias considerando que dichas leyes violaban el pacto federal de 1858. La legislatura ante la resolución del congreso nacional de no revocar las leyes que cuatro de los ocho Estados declararon inconstitucionales y ante las incursiones militares del gobierno general contra Nieto, estableció el 3 de julio de 1860 la separación del Estado de Bolívar de la Confederación para formar un nuevo pacto político con el Estado del Cauca. Además, Nieto fue nombrado general en jefe del "ejército unido de Bolívar y Magdalena” autorizado para abrir campañas militares sobre los Estados donde existan "enemigos armados que se opongan a la victoria de la causa federal"71.

Bajo estas circunstancias, los representantes de los Estados del Cauca (Manuel María Alaix) y Bolívar (José Araujo) firmaron en Cartagena el "Pacto de Unión” que creó los Estados Unidos de la Nueva Granada, asociación política a la que más tarde se sumarán Magdalena y Santander. El acuerdo designó como presidente de la Unión a Mosquera, subrogándole en su falta la presidencia a Nieto, y estableció que los Estados hostiles al pacto firmado serían sometidos militarmente y anexados por la fuerza ${ }^{72}$.

La instauración del pacto de unión entre Bolívar, Cauca, Santander y Magdalena, y su separación de la Confederación Granadina, motivaron la declaratoria de

da: primero, llamar a las legislaturas estatales para que convoquen una convención nacional; segundo, la suspensión de las acciones armadas, la reactivación de la comunicación entre los Estados y garantías para la libertad de imprenta que posibiliten la discusión de la situación nacional; tercero, el gobierno general deberá en la convención nacional incluir las reformas planteadas por los Estados y reforzar la constitución de 1858 para que cada localidad maneje a su conveniencia sus negocios internos, ver: El Heraldo, órgano del partido conservador, No 28, Bogotá, 11 de diciembre de 1860 , p. 3.

${ }^{71}$ Ley (27, diciembre, 1860) sobre autorizaciones al poder ejecutivo, en: Leyes de la asamblea legislativa del Estado de Bolívar 1860, Bogotá, Imprenta de la Nación, Edición oficial, p. 13.

${ }^{72}$ Tratado de unión y confederación de los Estados del Cauca y Bolívar bajo la denominación de Estados Unidos de la Nueva Granada; Adhesión del Estado soberano del Magdalena; Tratado de Unión y confederación entre los Estados soberanos de Santander y Bolívar; convenio sobre auxilios, celebrado entre los Estados de Bolívar y Santander, en: "Leyes de la asamblea legislativa del Estado de Bolívar 1860", pp. 25-30. 
guerra del gobierno general a dichos Estados73. De inmediato, los Estados con gobiernos conservadores aliados a Ospina (Cundinamarca, Boyacá y Antioquia) se prepararon para la guerra llamando a las armas a sus milicias para abrir campaña sobre los sublevados74.

En el Estado de Bolívar los conservadores fueron reprimidos para evitar una ofensiva contra Nieto y atenuar su participación en la región ante una posible guerra civil nacional. Los crímenes contra los conservadores en Cartagena fueron denunciados en distintos periódicos nacionales y locales: “...después de las iniquidades cometidas con el señor Juan Manuel Grau, cuya tienda fue saqueada oficialmente, los esbirros de Nieto han repetido las mismas tropelías con el señor Dionisio Araujo, patriota ilustrado y ardoroso, a quien no podían perdonar la audacia de haber publicado varias cartas en que ha confundido a los autores del criminal atentado del 26 de julio75."

En Corozal los conservadores denunciaron la constante imposición de empréstitos y expropiaciones, además de asesinatos selectivos en caminos alejados de la ciudad como mecanismos para debilitar a los vencidos. "En los recibos de expropiación no se determina la suma y las más de las veces estos recibos no se reparten a los expropiados cobrándose hasta 3 veces la suma decretada para cubrir los gas-

\footnotetext{
73 Decreto (5, julio, 1860) declarando en campaña el ejército de la confederación. Gaceta Oficial, No 2535, Bogotá, 186o, p. 445; Ley (16, abril, 1860) autorizando al poder ejecutivo para elevar el pie de fuerza en el presente año económico. Hasta 5000 hombres en tiempos de paz y disponer del tesoro de la nación para sostenerlo. Gaceta Oficial, No 2506, Bogotá, 1860, p. 305.

74 Decreto (23, mayo, 1860) recogiendo las armas del Estado en manos de particulares; Comunicación no. 11 (4, junio, 1860) al secretario de gobierno y guerra, poniendo a disposición del gobierno general 1000 hombres de milicia del Estado de Antioquia dispuestos a abrir campaña. Gaceta Oficial, No 2531, Bogotá, 1860, p. 425. Para conocer más sobre la formación de los cuerpos armados en el Estado de Boyacá ver: Dotor Robayo, María Victoria, "Soldados indios: la cuota de sangre del Estado soberano de Boyacá en el proceso de formación del ejército federal y del ejército de la Unión Colombiana", Historelo, 4 (8), Medellín, Universidad Nacional de Colombia, Julio- diciembre de 2012, pp. 73- 107.

75 El Porvenir, No 293, Bogotá, 27 de diciembre de 1859, p. 763. "Los individuos que a continuación se expresan quedan por la presente notificados: que al gobierno se le ha denunciado repetidas veces, y por personas caracterizados e imparciales, que ellos se ocupan constantemente de hablar en público contra el gobierno y de calificar dañadamente los actos y providencias de las autoridades. Por tanto, se les previene: que quedan desde hoy bajo la vigilancia de la policía, para proceder contra ellos en el momento que den motivo para hacerlo. Al efecto pondrán sus firmas al pie de esta boleta en señal de notificación. Federico N. Porras, José del C. Villa, Enrique Rodríguez, José Amador Guerrero, Manuel del Rio (hijo), Dionisio Villa, Gregorio Villa, Daniel Oliveros, Felipe de Olier, Diego de León, Hermógenes Rodríguez".
} 
tos de la guerra. A los acreedores no se les reconoce las deudas y los funcionarios del gobierno se enriquecen a costa del robo y el pillaje...76."

Para enfrentar a los "Estados rebeldes" el congreso nacional autorizó a Ospina para llamar al servicio activo a los jefes y oficiales de la Confederación, expulsar de la cámara de representantes a la diputación liberal del Magdalena, nombrar a Julio Arboleda como designado para ejercer el poder ejecutivo nacional, imponer a los dueños de bienes muebles e inmuebles expropiaciones y elevar el pie de fuerza pública en tiempo de paz a cinco mil hombres. Por último, la cámara de representantes envío una resolución a Ospina pidiéndole emplear la fuerza sobre el Cauca ${ }^{77}$. De esta manera, se promovió una guerra civil realizada por las burocracias estatales en representación de un partido político y con el respaldo de la fuerza pública de cada Estado por la inclusión o exclusión del poder público y el establecimiento de determinado orden institucional.

\section{Conclusión}

El proceso de construcción del Estado Nación colombiano debió enfrentar una intensa lucha política y militar, promovida por élites locales desde las diferentes regiones ante los repetidos intentos del gobierno central de monopolizar y controlar a las instituciones militar, judicial, eleccionaria y fiscal en las antiguas provincias de Cartagena, Sabanilla y parte de la de Mompós, convertidas en el Estado de Bolívar en 1857. La principal causa del conflicto político y militar partidista de 1859-1862 entre las burocracias armadas regionales del Estado de Bolívar y el gobierno general de la Confederación Granadina, fue promovida por la redefinición de la soberanía nacional y el establecimiento de leyes nacionales y locales que precisaban una relación de dominación entre los Estados federales y el gobierno nacional.

El monopolio partidista de los cargos públicos a nivel regional y nacional a partir del control de las elecciones, la milicia local y las rentas estatales, generaron los primeros enfrentamientos locales por el poder entre liberales y conservadores.

\footnotetext{
${ }^{76}$ El eco de Sotavento, No 7, Corozal, 15 de noviembre de 1861, p. 1.

77 Arboleda, Gustavo, "Historia contemporánea de Colombia...”, Tomo XII, p. 300; Informe que el secretario de Estado del despacho de gobierno y guerra de la Confederación Granadina dirige al congreso nacional de 1859, Bogotá, Imprenta de Francisco Torres Amaya.
} 
El conflicto trascendió a nivel nacional con la promulgación de la constitución de 1858 y las leyes nacionales de 1859, percibidas por los liberales excluidos del poder, como una violación a la autonomía regional y una estrategia del partido conservador para centralizar el poder. La creación de funcionarios nacionales para la inspección y control de la hacienda y milicia regional, articuló a las élites locales en facciones para enfrentar al gobierno central y negociar sus atribuciones en el Estado de Bolívar y los alcances de la soberanía nacional en la región caribe.

El conflicto político y militar se convirtió en el fenómeno que canalizó las formas de participación social y política que tuvieron su expresión, entre otras, en la formación de los partidos políticos y sus cuerpos armados, percibidos como ordenadores de la vida colectiva y cultural del país. Ante la imposibilidad de la resolución de los conflictos políticos por medios pacíficos, la guerra civil avanzó dentro de una dinámica incierta, la cual resolvió a través de la fuerza el reconocimiento de la legalidad y legitimidad de los vencedores, instaurando imposiciones y sometimientos que reestructuraron el orden social, político y económico, pero que por su arbitrariedad no resolvían los conflictos que, terminaron prolongándose hasta finales del siglo XIX.

El conflicto político y militar de 1859- 1862 brindó la posibilidad de dar autonomía a los Estados federales, asimismo, actuó como un elemento fundamental en la construcción del Estado colombiano y la instauración de un nuevo orden político, económico y social. La constitución de 1863 consolidó el poder político en manos de grupos socioeconómicos locales, los cuales, se encargaron de monopolizar la violencia y los recursos fiscales. De manera que para los vencedores, los liberales radicales, la guerra civil funcionó y valió la pena, en la medida en que reorganizó el poder a su favor por un periodo de veintidós años durante el federalismo. 


\section{Bibliografía}

\section{Fuentes Primarias}

\section{Biblioteca Nacional de Colombia (Prensa)}

El Camastrón, Santa Marta, 1860.

El Eco de Sotavento, Corozal, 1861.

El Heraldo, Bogotá, 1860, 1861.

El Liberal, Bogotá, 1858.

El Meteoro, Barranquilla, 1858.

El Núcleo, Bogotá, 1858.

El Porvenir, Bogotá, 1859, 1860.

El Progreso, Barranquilla, 1857.

El Registro Oficial, Cartagena, 1858.

El Tiempo, Bogotá, 1859.

El Tribuno, Cartagena, 1855.

Gaceta Oficial, Bogotá, 1856, 1857, 1859, 1860.

Gaceta Oficial del Estado de Bolívar, Cartagena, 1857, 1858, 1859, 1861.

Gaceta Oficial del Estado Federal del Magdalena, Santa Marta, 1858.

La Causa del Pueblo, Bogotá, 1859.

La Nueva Alianza, Cartagena, 1860.

La Patria, Bogotá, 1857, 1858.

La Reacción, Cartagena, 1858.

La Voz del Comercio, Cartagena, 1859.

La Voz del Comercio, Barranquilla, 1864.

Los Rabilargos, Santa Marta, 1859.

Un juicio imparcial. Unos imparciales, Hoja Suelta, Riohacha, 1855. 


\section{Biblioteca Luis Ángel Arango (Historiografía del siglo XIX y compilaciones documentales)}

Arboleda, Gustavo, Historia contemporánea de Colombia, desde la disolución de la antigua república de este nombre hasta el presente, Bogotá, Banco central Hipotecario, 1990, Tomo IX, X, XI.

Arboleda, Sergio, Diario de operaciones del ejército del sur de la confederación granadina, Bogotá, Banco de la república, 1994.

Bell Lemus, Gustavo (Comp.), Nieto Juan José, selección de textos políticos-geográficos e históricos, Bogotá, Ediciones gobernación del Atlántico, 1993.

Corrales, Manuel Ezequiel, Efemérides y anales del Estado de Bolívar, Bogotá, Imprenta de M. Rivas y Ca, 1892, tomo IV.

Constitución y leyes del Estado de Bolívar expedidas en 1857. Cartagena: Imprenta de E. Hernández, 1857.

Guerra, José Joaquín, Estudios históricos, Bogotá, Biblioteca Popular de cultura colombiana, 1952, tomo I.

Informe que el secretario de Estado del despacho de gobierno y guerra de la Confederación Granadina dirige al congreso nacional de 1859, Bogotá, Imprenta de Francisco Torres Amaya.

Leyes de la asamblea legislativa del Estado de Bolívar 1860, Bogotá, Imprenta de la Nación, Edición oficial.

Múnera, Alfonso (Comp.), Ensayos costeños. De la colonia a la república: 1770- 189o, Bogotá, Colcultura, 1994.

Nieto, Juan José, El ciudadano Juan José Nieto, gobernador suspendido de la provincia de Cartagena, ante los hombres honrados e imparciales de todos los partidos, Bogotá, Imprenta del neogranadino, 1855.

Nieto, Juan José. El ciudadano Juan José Nieto presidente constitucional del Estado Soberano de Bolívar, general en jefe del $4^{o}$ ejército de los Estados Unidos de Colombia. Bosquejo histórico de la revolución que rejeneró al Estado de Bolívar, Cartagena, Imprenta Ruiz e hijo, 1862.

Paula Borda, Francisco, Conversaciones con mis hijos, Bogotá, Biblioteca Banco popular, 1974, tomo I.

Parra, Aquileo, Memorias (1825-1875), Bogotá, Editorial Incunables, 1982.

Pérez, Felipe, Anales de la revolución escritos según sus propios documentos, Bogotá, imprenta del Estado de Cundinamarca, 1862.

Quijano Otero, José María, Diario de la guerra civil de 1860 y otros sucesos políticos, Bogotá, Editorial incunables, 1982. 
Restrepo, José Manuel, Diario político y militar, memorias sobre los sucesos importantes de la época para servir a la historia de la revolución de Colombia y de la Nueva Granada, desde 1849 para adelante, Bogotá, Imprenta nacional, 1954, tomo IV.

Restrepo Piedrahita, Carlos, Constituciones políticas nacionales de Colombia, Bogotá, Universidad Externado de Colombia, 1995.

Samper, José María, Los partidos políticos en Colombia, Bogotá, Incunables, 1984.

\section{Fuentes secundarias}

Abello, Ignacio, "El concepto de la guerra en Foucault", Revista de Estudios sociales, 14, Bogotá, Universidad de los Andes, Febrero de 2003.

Benedict, Anderson, Comunidades imaginadas. Reflexiones sobre el origen y la difusión del nacionalismo, México, Fondo de Cultura Económica, 1983.

Cardona Tobón, Alfredo, Los caudillos del desastre. Guerras civiles en el siglo XIX, Manizales, Hoyos Editores, 2006.

Dotor Robayo, María Victoria, "Soldados indios: la cuota de sangre del Estado soberano de Boyacá en el proceso de formación del ejército federal y del ejército de la Unión Colombiana”, Historelo, 4 (8), Medellín, Universidad Nacional de Colombia, Julio- diciembre de 2012.

Elías, Norbert, El proceso de la civilización. Investigaciones socio- genéticas y psicogenéticas, México, Fondo de Cultura Económica, 1987.

Fals Borda, Orlando, El Presidente Nieto: Historia doble de la Costa, Bogotá, Carlos Valencia Editores, 1981, Tomo II.

Foucault, Michel, Genealogía del racismo, Madrid, Ediciones de la Piqueta, 1992.

Koning, Hans Joachim, En el camino hacia la nación: nacionalismo en el proceso de formación del estado y la nación de la Nueva Granada, 1750-1856, Bogotá, Banco de la república, 1994.

Lemaitre, Eduardo, El general Nieto y su época, Bogotá, Carlos Valencia editores, 1983.

Muñoz Tejada, Julián Andrés, "La guerra civil de 1859: discursos sobre la construcción de un orden”, Revista diálogos de derecho y política, 4, Medellín, Universidad de Antioquia, Mayo- agosto de 2010.

Pardo, Luis Miguel, "Gobierno político y militar en el Estado soberano de Bolívar 18571886”, Anuario de Historia Regional y de las fronteras, 17 (2), Bucaramanga, Universidad Industrial de Santander, 2013. 
Pardo, Luis Miguel, “Las milicias del Estado Soberano de Bolívar, 1857- 1885”, Rueda Cardozo, Juan Alberto (ed.), Los ejércitos federales de Colombia, 1855-1886, Bucaramanga, Universidad Industrial de Santander, COLCIENCIAS, 2013.

Pinzón Lewin, Patricia, El ejército y las elecciones, Bogotá, CEREC, 1994.

Tilly, Charles, "Cambio social y revolución en Europa, 1492-1992”, Historia social, 15, España, Fundación Instituto de Historia Social, 1993.

Tilly, Charles, Coerción, capital y los estados europeos 990-1990, Madrid, Alianza Editorial, 1992.

Uribe, María Teresa y López Lopera, Liliana María, Las palabras de la guerra. Un estudio sobre las memorias de las guerras civiles en Colombia, Medellín, La Carreta editores, 2006. 